\title{
Reestructuración del sector hidrocarburífero argentino y «estrategia de acumulación» de capital en la convertibilidad*
}

\author{
Diego Pérez Roig \\ Consejo Nacional de Investigaciones Científicas y Técnicas (CONICET). \\ Centro de Estudios e Investigaciones Laborales (CEIL). \\ dperezroig@gmail.com
}

Recepción: 06-12-2018

Aceptación: 23-06-2019

Publicación: 01-07-2020

\section{Resumen}

El presente trabajo se inscribe en una temática de dilatada tradición en el campo de las ciencias sociales en Argentina. Por motivaciones tanto científicas como políticas, la evolución del sector hidrocarburífero ha sido un tópico recurrente en las discusiones acerca de las distintas «etapas de desarrollo» que se sucedieron en el país a lo largo del siglo Xx. En este sentido, el período abierto por la implementación de reformas neoliberales resulta relevante y ha concitado particular interés entre los investigadores. En el marco dado por un proceso general de reestructuración capitalista y metamorfosis de la forma de Estado, la industria petrolera sufrió profundos y perdurables cambios cualitativos. En este artículo analizamos las políticas de reorganización neoliberal del sector, en su articulación con las principales características de la «estrategia de acumulación» durante la etapa dominada por la convertibilidad (1989-2001). El cumplimiento de este objetivo pretende demostrar que la "comoditización" del petróleo y el gas —operada a través de la amplia desregulación y apertura del mercado a la competencia internacional - fue el reverso de la garantía del abastecimiento de combustibles para un modelo de crecimiento económico basado en el desarrollo de los sectores productivos. Para ello, recuperamos críticamente la bibliografía existente sobre el período, evaluamos cualitativamente las principales políticas implementadas y recurrimos al análisis cuantitativo de distintas variables económico-productivas. Entre sus resultados, el artículo sintetiza el carácter complejo de dicha articulación, así como los desafíos que quedarían planteados a la política hidrocarburífera del Estado una vez finalizada la etapa.

Palabras clave: neoliberalismo; Argentina; política hidrocarburífera; acumulación de capital; desarrollo

* Uno de los borradores de este artículo fue discutido en el marco de los proyectos de investigación UNQ y UBACYT: «La acumulación de capital en una "estructura dual” y los límites a la construcción de una hegemonía política: Argentina 1955-2015», dirigidos por el Dr. Adrián Piva. Agradezco a él y al resto de los integrantes la lectura atenta y los comentarios recibidos. 
Abstract. Restructuring of Argentine hydrocarbon sector and capital "accumulation strategy" during the convertibility regime

This article addresses a topic with a long tradition in the field of Social Sciences in Argentina. For both scientific and political reasons, the evolution of the hydrocarbon sector has been a relevant subject in the discussion regarding the consecutive "stages of development» all along the 20th century. In this sense, the period opened by the implementation of neoliberal reforms has attracted particular interest among researchers. In the framework of a general process of capital restructuring and metamorphosis of the State, the oil industry went through deep and lasting qualitative changes. The present paper analyses the policies of neoliberal reorganization of the hydrocarbon sector, in its articulation with the main characteristics of the capital «accumulation strategy» during the stage dominated by the convertibility regime (1989-2001). Fulfilling this objective, we try to prove that the commodification of oil and gas - operated through an extensive deregulation and market opening to international competition - was the reverse of the guarantee of fuel supply for a model of economic growth based on the development of the productive sectors. In order to do this, we critically assess the existing bibliography on the period, qualitatively appraise the main policies implemented and quantitatively analyse a set of economic-productive variables. Finally, the article synthetizes the complexity of such articulation, together with the dilemmas in which State's hydrocarbon policy would fall once the convertibility regime was over.

Keywords: neoliberalism; Argentina; hydrocarbon policy; capital accumulation; development

\author{
Sumario \\ 1. Introducción \\ 2. Mundialización y acumulación \\ en la convertibilidad \\ 3. Las transformaciones neoliberales \\ del sector hidrocarburífero
}

\title{
1. Introducción
}

A partir de 1989, en el marco de un proceso general de reestructuración capitalista y metamorfosis neoliberal de la forma de Estado, el sector hidrocarburífero argentino sufrió profundas transformaciones cualitativas. Hasta ese momento, pero especialmente durante la etapa de industrialización por sustitución de importaciones (ISI), la intervención del Estado se orientaba a satisfacer las necesidades del mercado interno con la perspectiva "estratégica» de abastecer de insumos al aparato productivo, así como de subsidiar energética y económicamente al capital en el espacio nacional de valor. Aun cuando en distintos momentos se hubieron implementado medidas de promoción y apertura a la inversión, el sector privado nunca había aportado más que una porción minoritaria de la producción, encontrándose subordinado a la dirección de la empresa estatal Yacimientos Petrolíferos Fiscales (YPF). Durante décadas, 
pues, la intervención política sobre el mercado había pretendido regular su funcionamiento de acuerdo a objetivos macroeconómicos generales emanados de la «estrategia de acumulación» imperante.

Si bien la dictadura de 1976-1983 tomó una serie de decisiones que socavaron la posición de YPF e incrementaron la gravitación del capital privado, la reestructuración profunda del sector comenzó en 1989, en el marco del radical programa de reformas impulsado por las fracciones más internacionalizadas de la burguesía. Con la principal excepción de Kozulj y Bravo (1993), las políticas de desregulación, privatización y federalización del dominio de los recursos, así como sus consecuencias en términos de composición y dinámica del mercado ampliado de petróleo y gas, fueron inicialmente abordadas desde una perspectiva predominantemente técnica (Caruso, 2003; Gadano, 1998; Gerchunoff, 1994; Kozulj, 2002; Pistonesi, 2001).

Los principales estudios del período orientados por la construcción conceptualmente informada de un problema de investigación y las reglas metodológico-procedimentales de la indagación social son, en efecto, de aparición relativamente reciente (Barrera, 2014; Mansilla, 2007; Sabbatella, 2013; Serrani, 2012). A un nivel más general, esta literatura se inserta en una larga tradición de estudios de la sociología económica y la sociología política acerca de la relación entre Estado y capital en los procesos de desarrollo de la periferia. Específicamente, en la de aquellos trabajos que han enfatizado el carácter «desindustrializador» del régimen de acumulación abierto en Argentina a mediados de los setenta (Azpiazu et al., 2003; Azpiazu y Nochteff, 1994; Basualdo, 2006; Schvarzer, 1998; entre otros), así como la desarticulación de las capacidades del Estado en el marco de las reformas neoliberales (Acuña, 1995; Azpiazu y Nochteff, 1994; Sidicaro, 2010; entre otros).

Mediante esta matriz interpretativa se han realizado destacables aportes al estado del conocimiento sobre la temática, a la vez que se han planteado sugerentes hipótesis de trabajo. Serrani (2012) realiza una aproximación a las transformaciones y tendencias del sector hidrocarburífero en ese período asumiendo como principio explicativo la existencia de "prácticas colusivas" entre Estado y empresarios. En los resultados de su análisis, el autor destaca la conformación y difusión de "ámbitos privilegiados de acumulación» —noción que recupera de Castellani (2009)—, así como la colonización empresarial de reductos estratégicos que deterioraron las capacidades del Estado y su «autonomía relativa" para disciplinar al capital petrolero. Barrera (2014), por su parte, analiza el proceso de "fragmentación» y privatización de YPF, en vistas de sus consecuencias sobre el mercado ampliado de hidrocarburos y las modalidades de intervención del Estado entre los años 1989-1999. En este estudio, el autor adopta una perspectiva analítica que tiene como eje las relaciones intraclase de las fracciones integrantes del «bloque de poder» gestado durante la última dictadura militar. Consecuentemente, propone considerar la fragmentación de la petrolera estatal y la reestructuración de la arquitectura del mercado como resultado de una colisión de intereses de distintos grupos, articulada por la posibilidad de maximizar beneficios dados por la apropiación de la 
renta petrolera y la enajenación del paquete accionario de YPF. Finalmente, Sabbatella (2013) analiza cualitativamente las mutaciones de la apropiación material y simbólica de los hidrocarburos que signan el tránsito del predominio del «nacionalismo petrolero» a la "hegemonía neoliberal». Para ello, se concentra en la forma y los conflictos mediante los cuales la mercantilización de los recursos cobró preeminencia a nivel de las representaciones de distintos actores, así como en su interpenetración con los intereses del sector privado. De esta manera, entre otras conclusiones, destaca el entrelazamiento de dicha "comoditización» con la vigencia de un régimen de acumulación centrado en la «valorización financiera», así como con la promoción de una forma de Estado «mínima».

En estos trabajos, el punto de partida epistemológico para el análisis de las transformaciones del Estado y la estructura económica - dado fundamentalmente por las relaciones entre fracciones integrantes del «bloque en el poder» y su vínculo con el aparato estatal (Poulantzas, 2001) — obscurece la consideración de contradicciones y procesos sociales de mayor alcance. De esta manera, se introducen sesgos a raíz de los cuales tienden a omitirse o malinterpretarse aspectos medulares del reordenamiento neoliberal de la industria hidrocarburífera. Aquí pretendemos superar las indagaciones hechas hasta el momento, asimilando sus resultados más significativos en otro enfoque de carácter interdisciplinario.

Nuestra principal inspiración proviene de una matriz multimétodo de análisis de políticas estatales propuesta por Oszlak y O’Donnell (1995) como parte de una agenda de investigación politológica acerca del Estado en América Latina. Dos aspectos de este enfoque nos interesan particularmente. Por un lado, la contingencia «estructural» que se atribuye a la actividad del Estado, y que aquí recuperaremos mediante distintos aportes críticos de las nociones convencionales de la ciencia política. Por el otro, la relevancia otorgada al «contexto agregado» del análisis, es decir, al conjunto de factores que exceden a las políticas estatales estudiadas, pero que resultan indispensables para comprenderlas, describirlas, explicarlas y evaluar sus efectos sobre otras variables. En este trabajo, daremos cuenta de dicho contexto empleando la categoría «estrategia de acumulación», herramienta intelectual que obedece a la problematización teórica y la dirección metodológica de la sociología económica. ${ }^{1}$ Como fundamentaremos más adelante, este conjunto de factores será trabajado desde la

1. Mediante esta categoría nos referiremos a las formas históricas de la acumulación de capital en la Argentina, asumiendo que sus características definen las necesidades de apropiación de los hidrocarburos en tanto que valores y valores de uso, así como los límites a la intervención del Estado en el marco de dicha apropiación. Siguiendo los estudios de la Escuela Francesa de la Regulación, Jessop (1991) y Hirsch (1994) emplean la noción de «estrategia de acumulación» para analizar la reformulación "posfordista» del Estado vis-à-vis el curso y los ritmos seguidos por el desarrollo capitalista. Nombran, así, un «modelo de crecimiento» económico específico resultante de múltiples interacciones contradictorias y «estructuralmente determinadas» de clases y grupos sociales, capaz de unificar los diferentes momentos en el circuito del capital bajo la "hegemonía» de una de sus fracciones. 
perspectiva de la internacionalización del capital, tomando en consideración sus implicaciones sobre los alcances y límites de la intervención estatal.

Así pues, a fin de contribuir a la comprensión de las transformaciones neoliberales de la industria petrolera en Argentina, el objetivo de este trabajo es analizar las políticas de reestructuración del sector hidrocarburífero, en su articulación con las principales características de la «estrategia de acumulación» de la convertibilidad (1989-2001). De esta manera, intentaremos demostrar dos proposiciones entrelazadas: a) la «estrategia de acumulación» emergente del período 1991-1994 no tuvo su centro en las finanzas sino en el desarrollo de los sectores productivos; b) en este marco, las políticas de desregulación implementadas en el sector petrolero fueron el reverso de la garantía del abastecimiento de combustibles para el ámbito doméstico y supusieron la apertura del mercado a la competencia internacional.

A continuación, el artículo se encuentra organizado en cuatro partes. En primer lugar, presentaremos los presupuestos históricos y metodológicos de nuestro enfoque, y daremos cuenta de las principales características de la "estrategia de acumulación» de la convertibilidad mediante el análisis estadístico de diversas variables económicas. En segundo lugar, con el propósito de estudiar la forma y los resultados de la reestructuración neoliberal del sector hidrocarburífero, consideraremos cualitativamente las políticas implementadas y recurriremos al análisis de datos cuantitativos suministrados por agencias estatales y privadas. Tanto en este como en el primer apartado, nuestra principal fuente será el Instituto Nacional de Estadística y Censos (INDEC); a fin de evitar repeticiones que entorpezcan la lectura, en el texto solo se referenciarán aquellos datos provistos por otras fuentes. En tercer lugar, articularemos los análisis precedentes, explicitando los puntos de contacto, así como el distanciamiento de nuestro trabajo respecto de investigaciones sociológicas previas. Finalmente, en las conclusiones, sintetizaremos los contenidos del artículo y presentaremos los desafíos que, como consecuencia de la reestructuración y la dinámica del sector durante la convertibilidad, quedarían planteados a la política hidrocarburífera del Estado una vez finalizada la etapa.

\section{Mundialización y acumulación en la convertibilidad}

Las transformaciones del Estado y la acumulación en Argentina inducidas por la implementación de políticas neoliberales son, con sus peculiaridades, expresión particular de un proceso de cambios del capitalismo ocurrido a escala global. Hacia fines de los sesenta, los límites de la reproducción del compromiso fordista-keynesiano comenzaron a manifestarse en el retroceso de la tasa media de ganancia, la depreciación de activos, procesos de estanflación y crónicos déficits fiscales, para derivar, pocos años después, en una crisis generalizada del capital y del Estado. El persistente deterioro de las condiciones de rentabilidad y de producción de consenso en los capitalismos centrales desencadenó un masivo proceso de relocalización de inversiones en capital fijo, así como de expansión y socialización de la deuda. Tanto espacial como temporalmente, esta "fuga» 
supuso la conversión de capital productivo en ingentes masas de capital-dinero (Harvey, 2007; Holloway, 1994). Las políticas neoliberales convalidaron tal reacción «ciega» frente a la crisis e intentaron reimponer la disciplina de mercado a través de mecanismos monetario-financieros y una amplia mercantilización de relaciones sociales, lograda merced a la apertura, desregulación y privatización de importantes sectores de la economía (Bonefeld, 1995; Bonnet, 2007).

Desde entonces, la rearticulación global de la acumulación sobre la base del surgimiento de espacios y sectores totalmente nuevos de la producción capitalista ha modificado la dinámica del «desarrollo desigual» entre regiones del planeta. Una ola de reestructuraciones y quiebras afectó a los capitalismos centrales, cuyas economías han tendido a desindustrializarse en términos relativos y a concentrar actividades de diseño y marketing, unidades de producción más «flexibles», servicios de alta innovación tecnológica, así como las más importantes plazas financieras (Arrighi, 1999; Harvey, 2008). Por su parte, en aquellas regiones donde los bajos costos de la fuerza de trabajo lo permitieron, se trasladó o continuó con la producción estandarizada, dando lugar a una suerte de "fordismo periférico» (Lipietz, 1986).

A lo largo de este proceso, desde diferentes enfoques y disciplinas de las ciencias sociales se ha señalado el acaecimiento de un cambio cualitativo en el orden capitalista mundial (Bina y Yaghmaian, 1991; Hardt y Negri, 2002; Palloix, 1975; Robinson y Harris, 2000), entre cuyas consecuencias metodológicas se encuentra la necesidad de internacionalizar la perspectiva de análisis de los fenómenos económico-políticos (Negri, 2004; Yaghmaian, 1998). Partiendo de estas premisas generales, compartimos que lo específicamente novedoso de las transformaciones de las últimas décadas es «la generalización planetaria del modo capitalista de extraer el excedente» (Astarita, 2004: 235).

Desde esta lectura, la mundialización no se reduce a la internacionalización de los procesos productivos, sino que implica una reorganización en profundidad de las relaciones sociales (Astarita, 2004). Se traduce, así, en un incremento de la presión competitiva y las constricciones del mercado mundial sobre los espacios nacionales. Ello rearticula orgánicamente al Estado en su relación con el capital, determinando nuevas posibilidades y límites de intervención (Hirsch, 1996; Jessop, 2002; Negri, 2004), en la medida en que tanto la acción de la ley del valor a escala global como las entradas y salidas masivas de flujos financieros sancionan las condiciones de valorización existentes en cada espacio nacional (Bonnet, 2002).

\subsection{La "estrategia de acumulación" de la convertibilidad}

La crisis de la industrialización sustitutiva en Argentina se entrelaza con estas transformaciones y es un momento de su desarrollo general. A mediados de los setenta, el «Rodrigazo» y el golpe militar abrieron una disputada reestructuración capitalista instigada por el reordenamiento del mercado mundial (Grigera, 2011). En los noventa, la recomposición de la hegemonía de las clases y fracciones dominantes fue mediada por el Estado a través de un doble proceso de transformación y fortalecimiento (Bonnet, 2008; Piva, 2012). 
La escalada hiperinflacionaria de marzo-abril de 1989 determinó la derrota de la alianza integrada por la clase obrera y las fracciones de mercado-internistas del capital que rechazaban el proceso de reestructuración. Su efecto más perdurable estuvo dado por una alteración decisiva de las relaciones sociales de fuerza que indujo, como en otros procesos similares, a aceptar democráticamente —en el sentido formal del término- las más drásticas políticas neoliberales (Anderson, 2003; Bonnet y Glavich, 1993, 1994; Harvey, 2005). Entonces, la crisis del Estado y el quebranto de sus empresas, así como la amenaza de un colapso de la acumulación y de la reproducción material de la sociedad en su conjunto, otorgaron potencialidad hegemónica a los intereses de las fracciones más concentradas del capital local, consistentes en una estrecha articulación del espacio nacional con el mercado mundial (Piva, 2012).

La clave de bóveda de esta hegemonía fue la implementación del Plan de Convertibilidad. En el marco de un amplio programa de desregulación y apertura de la economía local al mercado mundial, así como de privatizaciones y concesiones de empresas públicas (Alexander y Corti, 1993; Thwaites Rey, 2003), la restricción monetaria «sometió a la economía local a la acción del valor a escala mundial e indujo de este modo un acelerado proceso de reestructuración del capital» (Piva, 2012: 86). Bajo el régimen de paridad, la expansión en dólares de la base monetaria en pesos convertibles estaba sujeta al ingreso de divisas a través de las exportaciones, así como a la llegada de capitales. Ahora bien, tanto la mejora de la competitividad de la economía argentina como la atracción de flujos internacionales de capitales productivos y financieros, de los cuales en su conjunto dependían los resultados de la balanza de pagos, suponían un incremento constante de la productividad (Bonnet, 2008).

En este marco, el ciclo de auge de la convertibilidad (1991-1998) ${ }^{2}$ fue traccionado por sucesivos aumentos de la productividad del trabajo, logrados a través del aprovechamiento de la capacidad ociosa, la reorganización de los procesos productivos y, particularmente, la reconversión tecnológica posibilitada por el ingreso de capitales. Medida en dólares a precios constantes de 2010, en 1998 la formación bruta de capital fijo era un 164 \% más elevada que en 1990; la mayor tasa promedio anual de crecimiento se observa entre 1991-1994, con un 22,4 \% (Banco Mundial). Analizada tanto en precios de 1986 como de 1993, la inversión bruta interna fija (IBIF) se expandió más que el consumo en las fases de crecimiento y se retrajo en mayor medida en los años de caída. De este modo, su participación como porcentaje del PIB tuvo un marcado comportamiento procíclico. ${ }^{3}$ En cuanto a la composición, se observa un mayor dinamismo de las inversiones en equipo durable de producción

2. A precios de 1993, entre 1991-1998, el PIB se incrementó a una tasa anual del 5,2 \%. En la primera fase de crecimiento (1991-1994), lo hizo al 7,3\%. Después de la caída del 2,8 $\%$ de 1995, el crecimiento acumulado de 1996-1998 se ubicó en un $6 \%$.

3. Como porcentajes del PIB medido a precios de 1986, entre 1991-1994, el consumo pasó del 82,7 \% al 84,1 \%, mientras que la IBIF creció del 15,4\% al 21,1\%. Luego, a precios de 1993, entre 1996-1998, el consumo pasó del $81 \%$ al 81,5 \%, y la IBIF creció del $18 \%$ al 19,9 \% (Dirección Nacional de Cuentas Nacionales e INDEC). 
respecto de las correspondientes al rubro construcción, particularmente en el caso de maquinarias y equipos (Martínez et al., 1998). Como se desprende tanto del desagregado de la IBIF como del de las importaciones $\mathrm{CIF}^{4}$ por uso económico, la mayor parte de estas inversiones se basó en la compra de bienes de capital en el exterior. ${ }^{5}$ En las fases de crecimiento, el ahorro externo tendió a cubrir una porción cada vez mayor del financiamiento de esta renovación tecnológica. ${ }^{6}$

Entonces, es posible sostener que, en el ciclo 1991-1998, la acumulación de capital tuvo características "capital intensivas» (Aglietta, 1986), dadas por los incrementos de la productividad y la explotación resultantes de la reorganización de los procesos de trabajo y la incorporación de capital. La aproximación a estos fenómenos a partir de la Encuesta Industrial Mensual elaborada por el INDEC permite observar que, en esos años, la productividad por obrero ocupado y por hora trabajada se incrementó un $58,7 \%$ y un $54 \%$, respectivamente. Asimismo, en 1998 la intensidad laboral era un $3 \%$ más elevada que en 1991, y alcanzó picos en 1994 y 1997 en los que llegó a ser un 4,8 \% mayor. Entre 1991-1998, el cociente entre la productividad por obrero ocupado y el índice de salario por obrero deflactado por la inflación ${ }^{7}$ muestra un incremento de la explotación del $28 \%$. Es posible distinguir una primera fase de predominio de la extracción de plusvalor relativo e incremento de los salarios reales (1991-1994), ${ }^{8}$ y una segunda en la que se combinan la mayor productividad por hora trabajada y la tendencia a la caída de los salarios.

A la par del proceso de reestructuración del capital, el corazón de la acumulación adquirió un marcado sesgo industrial-exportador. A precios de 1986, entre 1991-1996, las exportaciones incrementaron un 25 \% su participación en el PIB (Dirección Nacional de Cuentas Nacionales); a precios de 1993, entre 1993-1998, el crecimiento fue del 51 \%. Asimismo, en 1998 las manufacturas de origen agropecuario (MOA) e industrial (MOI) representaban un $66 \%$ del total de exportaciones FOB $;{ }^{9}$ mientras que, en 2001, recesión y crisis

4. Cost, insurance and freight, término del comercio internacional marítimo que indica que en el precio de venta se adicionan los costos de transporte y seguro.

5. Entre 1991-1998, la compra de bienes de capital pasó de representar un 17,3 \% a un $27 \%$ del total de las importaciones CIF. A precios de 1986, entre 1991-1997, la participación de los bienes de capital importados sobre el total de la inversión en equipo durable de producción pasó del 15,5\% al 39,6\% (Martínez et al., 1998).

6. A precios de 1986, entre 1991-1997, el ahorro bruto nacional pasó de representar 100,3 \% a $77 \%$ de la inversión bruta interna. La menor participación se observa en 1994, con un $73,1 \%$ (ibíd.).

7. Anteriormente, este proxy fue utilizado por distintos autores: Gigliani y Bercovich (2006); Marticorena (2013); Piva (2015). Aquí utilizamos como deflactor del costo salarial real de las empresas el índice de precios internos al por mayor (IPIM) elaborado por el INDEC correspondiente a los productos manufacturados.

8. Entre 1991-1994, el índice de salario por obrero deflactado pasó de 75,9 a 108,3. A partir de allí, comenzó un proceso de caída, solo interrumpido por una leve recuperación entre 1998-1999.

9. Free on board, término del comercio internacional marítimo que hace referencia a la entrega de la mercancía en puerto y el traspaso de los riesgos o costos ulteriores de transporte al comprador. 
mediante, todavía mantenían un peso del 59 \%. Entre 1991-1998, medidas en cantidades, las exportaciones de MOA y MOI crecieron un $64 \%$ y un $164 \%$, respectivamente.

En el marco del proceso de "destrucción creativa» abierto por la convertibilidad, la contracara de aquella tendencia fue, ciertamente, la caída de la industria manufacturera en el valor agregado con relación al conjunto de la economía, ${ }^{10}$ o la quiebra de numerosas firmas y ramas que otorgaban mayor densidad al entramado productivo. En 1991, la industria manufacturera representaba el $54 \%$ del valor agregado bruto de los sectores productores de bienes y un 16,5\% del PIB. En 1998, esa gravitación se había reducido a un 50,6 \% y un 15,1\%, respectivamente. En efecto, en este período de crecimiento absoluto para el conjunto, la reestructuración no se desarrolló uniformemente por rubro de la producción, sino que tuvo resultados heterogéneos. Se expresó, así, un notable proceso de concentración, centralización e internacionalización de capitales (Basualdo, 2000; Kulfas y Schorr, 2000).

En los cuadros 1 y 2, tanto la variación del estimador mensual industrial (EMI) como la evolución del índice de volumen físico (IVF) en la industria manufacturera permiten un acercamiento al carácter bifronte de este proceso. Si bien la «reestructuración ofensiva» basada en cambios radicales en la organización de la producción, la incorporación de nuevos equipos y aumentos de la productividad y la competitividad fue un fenómeno transversal a las distintas ramas de la industria, en términos sectoriales se destacaron tres grupos (Kosacoff, 1993): (1) los establecimientos productores de insumos intermedios, intensivos en escala y capital, que alcanzaron indicadores productivos al tope de los estándares internacionales — siderurgia, petroquímica, aluminio, cemento y refinación de petróleo; (2) el complejo aceitero exportador, cuyo desarrollo comprende, además de las plantas fabriles, los sistemas de almacenamiento y transporte; ${ }^{11}$ (3) el complejo automotriz, reconvertido a una nueva lógica industrial destinada al mercado exportador a partir del ensamblado y la especialización en autopartes. La contracara del desempeño de estos sectores fue la caída o el estancamiento en ramas sensibles a la competencia internacional, (4) productoras de mercancías para el mercado interno y/o (5) de bienes con un mayor valor agregado relativo.

La reestructuración de los noventa consolidó, así, una serie de rasgos cuyo origen se encuentra en la crisis abierta a mediados de los setenta. Entre sus tendencias estructurales de largo plazo pueden mencionarse: el desplazamiento del centro de la acumulación hacia actividades manufactureras competitivas en el mercado mundial por ventajas comparativas «naturales»o «institucionales»,

10. Entre 1991-1998, el valor agregado de la industria como porcentaje del PIB cayó del 32,7 \% al $29 \%$. De punta a punta, entre 1989-2001, la retracción fue del 42,3 \% al $27 \%$ (Banco Mundial).

11. Vinculada a ello, debe mencionarse la reconversión de los métodos de producción del sector agropecuario posibilitada por una importante incorporación de tecnología. 
Cuadro 1. Variación del índice de volumen físico en la industria manufacturera (1991-1998).

\begin{tabular}{|c|c|c|c|c|c|c|c|c|}
\hline & $\begin{array}{l}\text { Elaboración } \\
\text { de productos } \\
\text { alimenticios y } \\
\text { bebidas (2) }\end{array}$ & $\begin{array}{l}\text { Elaboración } \\
\text { de productos } \\
\text { de tabaco }\end{array}$ & $\begin{array}{l}\text { Fabricación } \\
\text { de productos } \\
\text { textiles (4) }\end{array}$ & $\begin{array}{l}\text { Fabricación } \\
\text { de prendas } \\
\text { de vestir; } \\
\text { terminación } \\
\text { y teñido de } \\
\text { pieles (4) }\end{array}$ & $\begin{array}{l}\text { Curtido y } \\
\text { terminación } \\
\text { de cueros, } \\
\text { fabricación de } \\
\text { artículos de } \\
\text { marroquinería, } \\
\text { talabartería y } \\
\text { calzado y de } \\
\text { sus partes }\end{array}$ & $\begin{array}{l}\text { Producción } \\
\text { de madera y } \\
\text { fabricación } \\
\text { de productos } \\
\text { de madera y } \\
\text { corcho, excep- } \\
\text { to muebles, } \\
\text { fabricación de } \\
\text { artículos de } \\
\text { paja y materia- } \\
\text { les trenzables }\end{array}$ & $\begin{array}{l}\text { Fabricación } \\
\text { de papel y } \\
\text { productos } \\
\text { de papel } \\
\text { - }\end{array}$ & \\
\hline \multirow[t]{2}{*}{$\Delta$ '91-'98 } & $29,63 \%$ & $18,43 \%$ & $-22,72 \%$ & $-7,67 \%$ & $19,06 \%$ & $35,72 \%$ & $41,76 \%$ & \\
\hline & $\begin{array}{l}\text { Edición e } \\
\text { impresión; } \\
\text { reproducción } \\
\text { de grabaciones }\end{array}$ & $\begin{array}{l}\text { Fabricación } \\
\text { de coque, } \\
\text { productos de } \\
\text { la refinación } \\
\text { del petróleo y } \\
\text { combustible } \\
\text { nuclear }\end{array}$ & $\begin{array}{l}\text { Fabricación } \\
\text { de sustancias } \\
\text { y productos } \\
\text { químicos (1) }\end{array}$ & $\begin{array}{l}\text { Fabricación } \\
\text { de productos } \\
\text { de caucho y } \\
\text { plástico (1) }\end{array}$ & $\begin{array}{l}\text { Fabricación } \\
\text { de productos } \\
\text { minerales no } \\
\text { metálicos (1) }\end{array}$ & $\begin{array}{l}\text { Fabricación } \\
\text { de metales } \\
\text { comunes (1) }\end{array}$ & $\begin{array}{l}\text { Fabricación } \\
\text { de productos } \\
\text { elaborados de } \\
\text { metal excepto } \\
\text { maquinaria y } \\
\text { equipo (5) }\end{array}$ & \\
\hline \multirow[t]{2}{*}{$\Delta$ '91-'98 } & $65,51 \%$ & $2,88 \%$ & $39,88 \%$ & $63,07 \%$ & $25,13 \%$ & $53,00 \%$ & $6,65 \%$ & \\
\hline & $\begin{array}{l}\text { Fabricación de } \\
\text { maquinaria y } \\
\text { equipo n.c.p. }\end{array}$ & $\begin{array}{l}\text { Fabricación } \\
\text { de maquinaria } \\
\text { de oficina, } \\
\text { contabilidad e } \\
\text { informática (5) }\end{array}$ & $\begin{array}{l}\text { Fabricación } \\
\text { de maquinaria } \\
\text { y aparatos } \\
\text { electrónicos } \\
\text { n.c.p. (5) }\end{array}$ & $\begin{array}{l}\text { Fabricación de } \\
\text { equipos y apa- } \\
\text { ratos de radio, } \\
\text { televisión y } \\
\text { comunicacio- } \\
\text { nes }\end{array}$ & $\begin{array}{l}\text { Fabricación de } \\
\text { instrumentos } \\
\text { médicos, } \\
\text { ópticos y de } \\
\text { precisión, } \\
\text { fabricación de } \\
\text { relojes (5) }\end{array}$ & $\begin{array}{l}\text { Fabricación } \\
\text { de vehículos } \\
\text { automotores, } \\
\text { remolques y } \\
\text { semirremol- } \\
\text { ques (3) }\end{array}$ & $\begin{array}{l}\text { Fabricación } \\
\text { de equipo de } \\
\text { transporte } \\
\text { n.c.p. (5) }\end{array}$ & $\begin{array}{l}\text { Fabricación } \\
\text { de muebles } \\
\text { y colchones, } \\
\text { industrias } \\
\text { manufacture- } \\
\text { ras n.c.p. }\end{array}$ \\
\hline$\Delta$ '91-‘98 & $21,47 \%$ & $-56,91 \%$ & $-0,14 \%$ & $85,81 \%$ & $-40,35 \%$ & $140,42 \%$ & $2,80 \%$ & $75,07 \%$ \\
\hline
\end{tabular}

Fuente: elaboración propia en base a datos del INDEC.

pero de escasos eslabonamientos intraindustriales y agregación de valor; la concentración, centralización e internacionalización de capitales; la reducción del número de establecimientos y del empleo industrial (Azpiazu et al., 2001; Basualdo, 2006; Schorr, 2000). En virtud de nuestros supuestos, así como de los parámetros y la evidencia sobre los que se apoyan discusiones dentro de este campo a nivel internacional, entendemos que estos datos expresan un fenómeno complejo y relativo de alcance mundial (Grigera, 2013), más que un proceso absoluto de reversión de la industrialización o de "primarización» económica.

Ahora bien, tras el proceso de reestructuración y la reorientación del complejo industrial, la «estrategia» resultante se encontraría signada por la fragilidad externa de la acumulación. En primer lugar, debido a la tendencia al déficit de la balanza comercial en las fases de crecimiento. Entre 1991-1998, las exportaciones crecieron un $117 \%$ —pasando de 12.145 millones de dólares a 26.441 millones - mientras que las importaciones se incrementaron un $273 \%$ - de 8.402 millones de dólares a 31.403 millones. Las compras externas de bienes de capital, piezas y accesorios, y bienes intermedios son las que mayormente 
Cuadro 2. Variación del estimador mensual industrial (1994-1998).

\begin{tabular}{|c|c|c|c|c|c|c|}
\hline & $\begin{array}{l}\text { Alimentos y } \\
\text { bebidas (2) }\end{array}$ & $\begin{array}{l}\text { Productos del } \\
\text { tabaco (4) }\end{array}$ & $\begin{array}{l}\text { Productos } \\
\text { textiles (4) }\end{array}$ & Papel y cartón & $\begin{array}{l}\text { Edición e } \\
\text { impresión }\end{array}$ & $\begin{array}{l}\text { Refinación del } \\
\text { petróleo (1) }\end{array}$ \\
\hline$\Delta^{\prime} 94-98$ & $10,84 \%$ & $0,29 \%$ & $-4,61 \%$ & $9,82 \%$ & $30,41 \%$ & $17,05 \%$ \\
\hline & $\begin{array}{l}\text { Sus. y prod. } \\
\text { químicos (1) }\end{array}$ & $\begin{array}{l}\text { Caucho y } \\
\text { plástico }\end{array}$ & $\begin{array}{l}\text { Minerales no } \\
\text { metálicos (1) }\end{array}$ & $\begin{array}{l}\text { Industrias } \\
\text { metálicas } \\
\text { básicas (1) }\end{array}$ & Automotores (3) & $\begin{array}{l}\text { Metalmecánica } \\
\text { exc. automot. (5) }\end{array}$ \\
\hline$\Delta$ '94-'98 & $26,79 \%$ & $13,90 \%$ & $9,87 \%$ & $25,84 \%$ & $10,78 \%$ & $-10,98 \%$ \\
\hline
\end{tabular}

Fuente: elaboración propia en base a datos del INDEC.

explican este fenómeno. ${ }^{12}$ En segundo lugar, a raíz de la inserción en el mercado mundial en base a la exportación de manufacturas de bajo valor agregado y el deterioro de los términos de intercambio. Después de las crisis asiática (1997) y rusa (1998), los precios de exportación cayeron más acentuadamente que los de las importaciones, disminuyendo el poder de compra internacional de los productos argentinos — tendencia que se prolongó hasta 2001.13 En tercer lugar, y como consecuencia de las dos dimensiones anteriores, por motivo de la dependencia financiera. Como vimos, una parte creciente de la modernización tecnológica fue apalancada por la ampliación del crédito posibilitada gracias al ahorro externo. Entre 1991-1998, período con centro en la reproducción ampliada del capital, el comportamiento procíclico de las importaciones y la inyección de liquidez en el mercado interno dispararon el crecimiento de la deuda externa. ${ }^{14}$ Como consecuencia de los resultados negativos de la balanza comercial y el incremento del pago de intereses, se observa, entonces, una acumulación de sucesivos déficits por cuenta corriente que agudizó el estrangulamiento externo de la «estrategia de acumulación». ${ }^{15}$

En la medida en que el respaldo de la inversión productiva y de los desequilibrios macroeconómicos pasó a depender cada vez más del circuito financiero internacional, la economía local agudizó su vulnerabilidad respecto de los reflujos repentinos y masivos de capitales. Esta afluencia, crucial como «sutura» del ciclo de acumulación, se mantuvo mientras existieron expectativas positivas respecto de las condiciones de empleabilidad de la fuerza de trabajo y no ocurrieron perturbaciones externas. Durante la segunda mitad de la década, tanto

12. Entre 1991-1998, las compras externas de bienes de capital crecieron un 492,3\%, las de piezas y accesorios para bienes de capital al 346,5\% y las de bienes intermedios al $193 \%$. En 1998, estas importaciones guardaban un peso sobre el total del $27 \%, 17,5 \%$ y $31,9 \%$, respectivamente.

13. Entre 1996-2001, el índice de términos de intercambio se redujo un $8,45 \%$.

14. De 61.335 millones de dólares en diciembre de 1991 a 140.731 millones en diciembre de 1998.

15. Entre 1992-1994, el déficit por cuenta corriente pasó de 5.521 millones de dólares a 10.981 millones (4,38 \% del PIB). Después de una caída en 1995 motivada por la recesión de ese año, volvió a incrementarse en la fase 1996-1998, pasando de 6.755 millones de dólares a 14.465 millones (5\% del PIB). 
el incremento de las presiones competitivas internacionales como la salida de capitales ocasionada por la dinámica interna del conflicto social ${ }^{16}$ desataron una fase recesiva frente a la cual solo pudo apelarse a mecanismos deflacionarios de desahogo - ajuste fiscal y reducciones salariales_-, así como a aumentos en la extracción de plusvalía absoluta.

\section{Las transformaciones neoliberales del sector hidrocarburífero}

La reestructuración del capital previamente caracterizada magnificó la demanda energética de la acumulación. El crecimiento de la producción y el incremento de la participación industrial en las exportaciones se expresaron en las tendencias y especificidades sectoriales del consumo de energía. En el período 19892001, se produjo un importante crecimiento del total, que pasó de 30.113 $\mathrm{kTEP}^{17}$ a 40.857 kTEP; este aumento fue sostenido entre 1989-1999, año en que alcanzó los 43.056 kTEP (Secretaría de Energía de la Nación). La incidencia del petróleo y el gas en la matriz energética se mantuvo estable en un promedio del $86 \%$, y todos los sectores productivos (industria, agropecuario y transporte) tuvieron un importante crecimiento hasta 1998, para luego iniciar una caída que se prolonga más allá del período que analizamos ahora.

Como puede observarse en el gráfico 1, el aumento del consumo de energía entre 1990-2001 fue relevante, inclusive, si lo comparamos con otros períodos.

La importancia de la energía para la reproducción de la «estrategia de acumulación" de estos años se observa más cabalmente en el cuadro 3, donde damos cuenta del comportamiento procíclico del consumo.

En otro nivel de abstracción, esta correlación expresa al suministro energético como aspecto del entorno en el cual las unidades privadas e independientes de capital deben basar su reproducción. Como proceso simultáneo de valorización del valor y de trabajo concreto, la reproducción capitalista crea una masa acrecentada de valor que se traduce en la producción de un mayor volumen de objetos de uso (Grossmann, 1979). De modo tal que, en la reproducción del capital, no solo ocurre una sustitución del valor, sino también una sustitución material (Rosdolsky, 2004). Tanto en la producción como en la circulación de mercancías, ella supone un continuo incremento de la demanda de energía que no puede ser satisfecha únicamente por la acción individual de los capitales en competencia (Altvater, 1977).

Así pues, la conformación de esta «naturaleza social» recae inicialmente dentro del círculo de atribuciones generales del Estado, dada su inmediata sustracción de la necesidad de obtener plusvalor. Sin embargo, es preciso recordar que tal "garantía» estatal de los prerrequisitos materiales de la producción solo se concretiza históricamente, mediada por las cambiantes condiciones de la lucha

16. En este sentido, para evaluar el comportamiento de los capitales del sector hidrocarburífero, no es un factor superfluo el estallido de protestas sindicales, piquetes y puebladas en distintas comarcas petroleras (Klachko, 2002; Petruccelli, 2005; Piva, 2012).

17. Miles de toneladas equivalentes de petróleo. 
Gráfico 1. Variación anual acumulada del consumo de energía. Sectores productivos y total, varios períodos

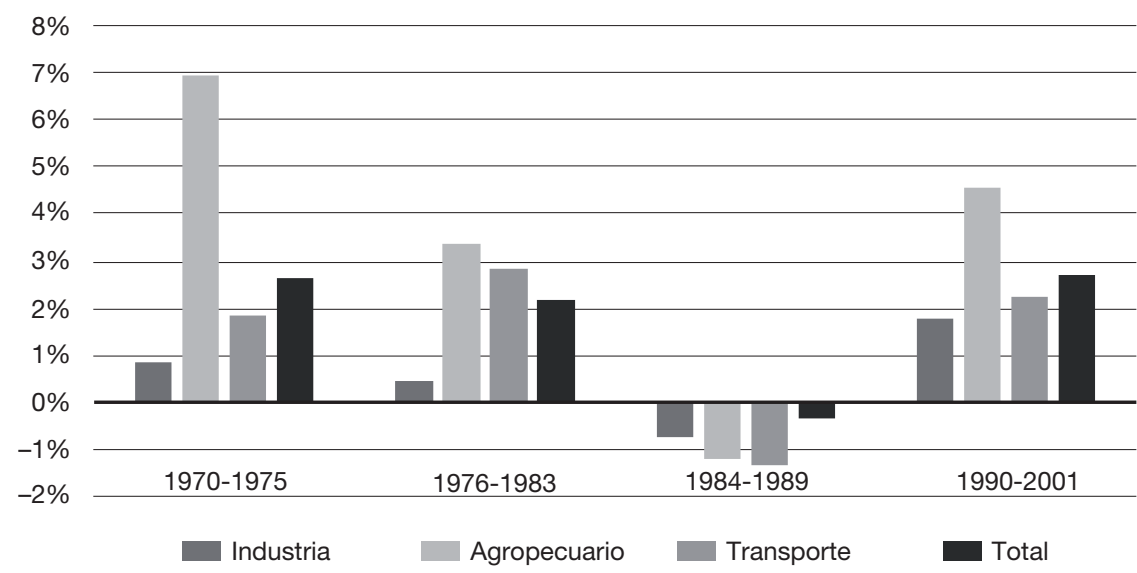

Fuente: elaboración propia en base a datos de Secretaría de Energía de la Nación.

Cuadro 3. Crecimiento anual acumulado del consumo de energía por sectores.

\begin{tabular}{lcc}
\hline & \multicolumn{2}{c}{ Crecimiento anual acumulado } \\
\cline { 2 - 3 } & $1990-2001$ & $1991-1998$ \\
\hline Industria & $1,75 \%$ & $3,73 \%$ \\
Agropecuario & $4,54 \%$ & $6,82 \%$ \\
Transporte & $2,26 \%$ & $5,44 \%$ \\
Comercial y público & $1,36 \%$ & $0,65 \%$ \\
Residencial & $3,66 \%$ & $3,42 \%$ \\
Total & $2,71 \%$ & $4,46 \%$ \\
\hline
\end{tabular}

Fuente: elaboración propia en base a datos de Secretaría de Energía de la Nación.

de clases y la valorización de capital (Hirsch, 1978). Ello supone que la política infraestructural-energética del Estado se encuentra abierta a una multiplicidad de formas y aporías que no siempre adoptan una dirección «estatizante»o meramente funcional a las necesidades de la acumulación. Como veremos, en su articulación con las características de la convertibilidad, la intervención estatal y la dinámica del sector asimilaron una serie de tendencias predominantes a nivel mundial que se entrelazaron con el proceso de reestructuración del capital y metamorfosis del Estado que sucedió a la crisis hiperinflacionaria.

\subsection{Tendencias a nivel internacional}

Desde mediados de los setenta, las transformaciones globales promovidas por las políticas neoliberales se articularon con la reorganización del mercado internacional resultante de la mayor injerencia de los países de la OPEP en la 
administración de la oferta primaria, la captación de renta y el control de las reservas (Mitchell, 2011; Roberts, 2004; Yergin, 2008). Durante las siguientes dos décadas, estos cambios reforzaron la competencia, así como la presión sobre aquellos recursos no controlados por los miembros del cártel, alentando modificaciones en los paradigmas de gestión y en el posicionamiento de distintos actores (Toledo Tolentino, 2011).

En primer lugar, bajo las premisas del value based management, muchas compañías tendieron a concentrarse en sus actividades más rentables y en las operaciones posibilitadas por la incorporación del petróleo a distintos mercados financieros (Labban, 2010). Los procesos de reestructuración interna y recorte de gastos implicaron la venta de numerosos activos; la reducción de inversiones destinadas a la incorporación de reservas; el desprendimiento de áreas maduras o marginales; así como la subcontratación de aquellos eslabones de la cadena productiva considerados no esenciales o demasiado costosos. Un resultado destacable de esta reorganización es la creciente importancia de empresas de servicios que acaparan prestaciones de alta especialización tecnológica (Barreau, 2002).

En segundo lugar, en el marco de la crisis de la deuda y la caída de los precios internacionales, a partir de mediados de los ochenta se produjo un doble movimiento. Por un lado, una creciente interpenetración de empresas estatales con capitales internacionales. Ante la falta de recursos financieros, organizacionales o tecnológicos, muchos países de la OPEP se vieron forzados a desregular y a privatizar parte de su industria, alentando un proceso de articulación entre sus operaciones upstream y el reingreso de compañías transnacionales (Rodríguez-Padilla, 1991). A su vez, empresas de distintos países productores comenzaron a controlar o a participar de asociaciones en el segmento downstream con pares occidentales, tanto en sus propios mercados como en los de los Estados consumidores (Abdalla, 1995).

Por otro lado, primero en Estados Unidos a raíz del boom bursátil de los noventa, y luego a nivel global tras la severa caída de las cotizaciones ocasionada por la crisis asiática, se desencadenó una notable centralización de capitales (Toledo Tolentino, 2011). Las distintas fusiones y adquisiciones de esta ronda no solo posibilitaron mayores recortes de gastos, sino también mejoras de los indicadores de reservas y producción que permitieron valorizaciones accionarias sin los riesgos implicados en la actividad exploratoria.

\subsection{Reestructuración neoliberal del sector hidrocarburifero argentino}

En el ámbito local, estas transformaciones se articularon con los factores internos que derivaron en la desregulación del mercado y la privatización de YPF. Ante el quebranto del Estado y sus empresas, ${ }^{18}$ la política hidrocarburífera se

18. Entre 1975-1986, YPF registró doce años consecutivos de pérdidas. La instrumentación de distintas medidas compensatorias y desreguladoras posibilitó que, desde fines del alfonsinismo (1987-1988) y hasta comienzos del menemismo (1990), volvieran a obtenerse leves resultados positivos en la relación utilidades sobre ventas. Como demuestra Barrera (2014), la mayor parte de aquel quebranto se explicaba, directamente, por la implementación de 
orientó a potenciar la inversión privada con los propósitos de garantizar el abastecimiento de energía del relanzamiento de la acumulación y de obtener divisas mediante la exportación. Ello determinó un temprano alineamiento de la intervención estatal con los intereses de distintas fracciones o grupos de la burguesía, así como una apertura general del sector al arribo de capitales provenientes del exterior. En pocos meses, mediante el fortalecimiento de la participación privada y la eliminación de regulaciones estatales, un paquete de leyes generales ${ }^{19} \mathrm{y}$ decretos específicos generó condiciones estructurales y de largo plazo para que el mercado acogiera la competencia e internacionalización de los capitales petroleros.

Entre sus disposiciones más importantes, los decretos no $1.055,1.212$ y 1.589, dictados entre octubre y diciembre de 1989, sentaron las bases de la licitación de áreas de «interés secundario» para su exploración, desarrollo y explotación por el capital privado, así como de la asociación de YPF en áreas centrales; reconvirtieron en concesiones de explotación o asociaciones los contratos por los que YPF recibía cuotas de crudo; ${ }^{20}$ permitieron la libre disponibilidad de los hidrocarburos y sus derivados; establecieron un nuevo sistema de precios «libremente pactados» en todas las etapas del sector, ${ }^{21}$ eliminaron las restricciones en cuanto a la cantidad de concesiones de explotación y permisos de exploración a ser detentados por privados; permitieron la libre disponibilidad de hasta el $70 \%$ de las divisas obtenidas por la exportación, así como la libre importación de petróleo y derivados sin autorización ni cobro de aranceles; y liberalizaron la instalación de refinerías y bocas de expendio. Todo ello, como respuesta a la "prioritaria necesidad» de promover y ejecutar «planes destinados a incrementar la producción nacional de hidrocarburos líquidos y gaseosos, incluyendo sus derivados para asegurar el autoabastecimiento interno y un adecuado margen de reservas». ${ }^{22}$

Por su parte, el decreto $\mathrm{n}^{\circ} 2.778$, del 31 de diciembre de 1990, transformó YPF en una sociedad anónima de capital abierto y aprobó el Plan de Transformación de la empresa. Según se argumentaba entonces, la reestruc-

políticas que habían perjudicado a la compañía durante la dictadura militar. Sin embargo, más allá de esta causalidad inmediata, aquello que cobraba expresión - tanto en la situación de YPF como en las directivas «externas» que afectaban su performance corporativa- era la crisis del Estado y la reestructuración abierta a mediados de los setenta.

19. Entre las normas de carácter general que sirvieron de marco, se encontraban las leyes de Reforma del Estado no 23.696/89 y de Emergencia Económica no 23.697/89, así como los decretos $n^{\circ} 1.224 / 89$ de Suspensión del Compre Nacional y no 1.225/89 de Régimen de Inversiones Extranjeras.

20. Las áreas marginales y centrales, así como las que estaban reguladas por contratos, fueron cedidas en calidad de concesiones a 25 años, a partir del pago de un canon relacionado con la cantidad de reservas.

21. En el caso del gas natural, el precio abonado por usuarios y productores continuaría estando fijado por la Secretaría de Energía hasta que existiera un mercado con múltiples oferentes.

22. Decreto $\mathrm{n}^{\circ} 1.055 / 89$, artículo $1^{\circ}$. En el mismo sentido se redactó, por ejemplo, el artículo $3^{\circ}$ de la ley no 24.076/92, de privatización de Gas del Estado. 
turación tenía como finalidad potenciar su eficiencia y valor, así como continuar fomentando la competencia (Barrera, 2014; Sabbatella, 2013; Serrani, 2012). De esta manera, sobre la base de un estudio elaborado por la consultora McKinsey \& Company, se dispuso la concesión o la asociación con operadoras privadas en distintas áreas de exploración y explotación; la asociación o el desprendimiento de activos (ductos y refinerías); la supresión de áreas del negocio consideradas subcomerciales (como el mantenimiento de la flota); la «racionalización» de personal; y la participación en los mercados bursátiles.

Como resultado inmediato de esta política, puede observarse una reorganización del mercado de la que, a través de distintos mecanismos, resultó particularmente beneficiado un puñado de capitales locales - Pérez Companc, Bridas, Astra, Pluspetrol, CGC y Tecpetrol (Kozulj y Bravo, 1993). En este proceso, que se extiende entre 1989-1993, el sector privado pasó a controlar un total de 147 áreas, que representaban el $40 \%$ de las reservas comprobadas y el $53 \%$ de la extracción de gas natural, así como el $55 \%$ de las reservas comprobadas y el $62 \%$ de la extracción de petróleo (Barrera et al., 2012). A su vez, asociadamente junto a otros capitales externos, aquel grupo de empresas tomó posesión de activos surgidos de la reestructuración de YPF que posibilitaron la concreción de estrategias de integración vertical e inserción internacional. Como contrapartida, el Estado obtuvo ingresos por 2.059 millones de dólares (Kozulj, 2002) e YPF experimentó, entre 1991-1993, una caída del 40 \% de sus reservas y de un $25 \%$ de la extracción de crudo (Serrani, 2012).

Existe una aparente inconsistencia entre este resultado inmediato y los principios que doctrinariamente orientaban las transformaciones. Durante esta primera etapa de reestructuración, los capitales locales más concentrados obtuvieron amplios beneficios que elevaron sus niveles de rentabilidad. Es correcto interpretar que, de tal manera, resultaron «compensados» frente a las pérdidas que suponían para ellos la privatización y la supresión de los contratos con la empresa estatal (Barrera, 2014), exigencia de la que participaban acreedores del Estado, inversores financieros y la banca extranjera. Ahora bien, si tanto en esta como en el conjunto de las privatizaciones se modulaban distintas pujas interburguesas, era porque de su trámite dependía la posibilidad de constituir un nuevo «bloque en el poder» que consolidara las correlaciones de fuerza emergentes tras la crisis hiperinflacionaria, así como la alternativa hegemónica planteada en resolución a ella. Recordemos que, como en otros procesos de reestructuración a nivel global, solo a través del disciplinamiento de la burguesía por medio de los mecanismos de la competencia internacional era posible reencauzar la subordinación de la clase obrera. La persecución de este interés estratégico, que aúna al capital en su relación antagonista con el trabajo, explica que las privatizaciones constituyeran una «identidad objetiva de intereses» (Salvia y Frydman, 2004) y operaran, así pues, como "prenda de unidad entre las distintas fracciones de la gran burguesía» (Bonnet, 2008: 292). Pese a sus resultados inmediatos, en el marco dado por la reestructuración, la industria petrolera no quedaría sustraída de las presiones competitivas del mercado mundial. 
En esta primera etapa, la agresividad con la que se aplicaron las reformas en el sector hidrocarburífero coincide con la ofensiva general del capital del período julio/1989-abril/1991. Los sucesivos decretos de desregulación, apertura y eliminación de la intervención estatal profundizaron el sometimiento del ámbito doméstico a la coerción de la competencia y la dinámica internacional de precios, ${ }^{23}$ de tal modo que incentivaron la implementación de nuevas estrategias de gestión, extracción, industrialización y comercialización de la producción. Si, por un lado, los grupos de la burguesía local beneficiados magnificaron su proceso de acumulación, por el otro, fueron empujados a emprender estrategias de internacionalización.

Tecpetrol obtuvo concesiones de explotación en varias provincias que posibilitaron el posterior desarrollo de negocios midstream y downstream, así como el acceso a áreas productivas en Venezuela, Brasil, Ecuador, Colombia, Perú, México, Bolivia y Estados Unidos. Pluspetrol, fundada en 1976 por las familias Rey y Poli, comenzó como contratista de YPF en tareas de recuperación secundaria de pozo. Gracias a los sucesivos planes de apertura a la inversión privada, pero, fundamentalmente, tras la reestructuración del sector en los noventa, comenzó a desarrollar operaciones en Bolivia, Perú, Colombia, Venezuela y Angola.

Trayectorias similares se observan en los casos de otras compañías de origen nacional que, durante la convertibilidad, iniciaron o potenciaron sus planes de internacionalización para luego ser absorbidas en la estrategia global de capitales más concentrados. En 1996, después de una puja con Pérez Companc, CGC y Texaco, Repsol adquirió Astra, entonces propiedad de la familia Grunensein. Era la sexta productora nacional de crudo y también contaba con actividades upstream en Venezuela. En 1997, a través de Astra, los españoles pasaron a controlar activos equivalentes al $45 \%$ del paquete accionario de Pluspetrol. Ese mismo año, Bridas se fusionó con Amoco para dar origen a Pan American Energy. Entonces, la petrolera de los hermanos Bulgheroni era la cuarta mayor productora de petróleo del país y operaba en Perú, Bolivia, Brasil, Paraguay, Chile, Rusia y Asia Central.

En 1999, Chevron desembolsó casi 1.000 millones de dólares para quedarse con Petrolera Argentina San Jorge (PASJ), empresa formada a comienzos de los sesenta por Jorge Priú y Guillermo Ostry, dos exfuncionarios de YPF. Durante los noventa, PASJ se mantuvo entre las principales productoras de petróleo y llegó a ser la segunda mayor exportadora, detrás de YPF. Al momento de su venta, contaba con 22 concesiones de explotación en Argentina y 8 bloques de exploración en Colombia, Ecuador, Perú, Bolivia y Chile.

Por último, en octubre de 2002, PECOM fue adquirida por Petrobras. Previamente beneficiada por las "privatizaciones periféricas» de la dictadura, en los noventa la petrolera de la familia Pérez Companc accedió a concesiones de explotación que la convirtieron en la segunda productora de petróleo del país

23. La brecha de precios entre el barril de WTI y el precio interno promedio se redujo del 44 $\%$ en 1989 al 6,2 \% en 2000 (Kozulj, 2002). 
y en una de las principales exportadoras - con ventas externas que alcanzaron alrededor del $30 \%$ de su extracción (Secretaría de Energía de la Nación). $\mathrm{Al}$ momento de su venta, contaba con operaciones upstream en Venezuela y Ecuador, países donde concentraba el $55 \%$ del total de sus reservas probadas (PECOM Energía, Memoria y Estados contables al 31 de diciembre de 2002).

La privatización y la posterior enajenación de YPF también estarían signadas por el entrelazamiento de factores internos y externos. En esta última etapa, la metamorfosis de la forma estatal, la desregulación del mercado y la internacionalización del capital petrolero se articularon con los desequilibrios de la «estrategia de acumulación». Por un lado, YPF debía acoplarse definitivamente a un mercado abierto y competitivo para el cual el petróleo interesaba en cuanto que commodity. Esta modificación en la «valoración simbólica» (Sabbatella, 2013) de los hidrocarburos era consecuencia de la propia reestructuración en ciernes. En el marco por ella configurado, la empresa debía abandonar su antigua orientación "estratégica», para adoptar nuevos criterios de racionalidad y eficiencia dados por la lógica de la valorización de capital.

Por otro lado, la convertibilidad había vetado el financiamiento estatal inflacionario, razón por la cual el equilibrio fiscal solo podía lograrse reduciendo el gasto, incrementando los ingresos o, de no resultar aquello suficiente, apelando al endeudamiento y la venta de bienes públicos. En 1992, YPF no solo era el principal activo en propiedad del Estado, sino que su privatización resultaba ineludible para el cumplimiento de las metas pactadas con el FMI. Asimismo, se consideraba que la modalidad escogida para la operación a través del método book building y una oferta pública inicial de acciones abriría el camino para la inserción internacional de otros títulos y papeles, contribuyendo a presentar al país como un destino «seguro» para la inversión privada (Serrani, 2012).

En septiembre de 1992, la ley $\mathrm{n}^{\circ} 24.145$ ratificó lo dispuesto por el decreto $\mathrm{n}^{\circ} 2.778 / 90$ y dividió el capital social de la empresa en acciones de distintos tipos. $\mathrm{Al}$ menos un $50 \%$ debía venderse en las bolsas de valores en el plazo máximo de tres años, conservando el Estado nacional como mínimo un $20 \%$ hasta la sanción de una nueva ley. ${ }^{24} \mathrm{~A}$ fin de legitimar socialmente el proceso de enajenación, la totalidad de lo recaudado por las acciones Clase A debía destinarse al régimen de previsión social, con vistas al financiamiento de incrementos de los haberes jubilatorios.

Con similar propósito, la ley dispuso la federalización del dominio originario de los hidrocarburos, así como la reparación de las deudas que la nación había contraído con las provincias productoras por regalías mal liquidadas. Según se argumentaba, la provincialización permitiría a los estados subnacionales captar una mayor parte de la renta hidrocarburífera y conduciría a una democratización de la gestión del sector (Sabbatella, 2013). Esta concesión -que era parte del proceso general de descentralización de aparatos y funciones del Estado (Oszlak, 2003) — atendía aspiraciones latentes a lo largo de

24. Esta fue una concesión a aquellos sectores del oficialismo que no veían con agrado el desprendimiento total de la empresa. 
la historia petrolera argentina (Gadano, 2006; Kaplan, 1992) y fue una pieza clave del consenso en torno a la radical transformación de la industria. ${ }^{25}$

La primera oferta se realizó en junio de 1993 y alcanzó al 45 \% de las acciones de YPF. A diferencia del proceso de reestructuración, los principales participantes fueron inversores institucionales. Distintos autores coinciden en que la determinación adoptada por el Gobierno a fin de retener a estos compradores -en el marco de una fuerte demanda, se optó por mantener el precio de la acción en torno a los 19 dólares-implicó una importante subvaluación de la empresa (Barrera, 2014; Kozulj, 2002; Mansilla, 2007). Después de esta primera etapa de venta, el paquete accionario quedó repartido en un $20 \%$ para el Estado nacional; un $12 \%$ para las provincias; un $12 \%$ para jubilados; un $10 \%$ para personal, y un $46 \%$ en manos de inversores privados.

En marzo de 1995, ya bajo las consecuencias del «efecto tequila», el Gobierno logró que la ley no 24.474 eliminara la obligación de mantener el $20 \%$ de las acciones en manos del Estado. ${ }^{26}$ Sin embargo, en enero de 1999, en el marco de la crisis brasileña y la fuerte devaluación del real, se dispuso la venta de un 14,99\% de los títulos. El oferente que accediera a ese porcentaje tendría derecho a colocar dos ejecutivos en el directorio, razón por la cual el Gobierno fijó el precio de las acciones un $33 \%$ por encima de la cotización del día (Barrera, 2014).

Entonces, «YPF tenía presencia en 12 países, en tres continentes y había pasado de ser una compañía exclusivamente argentina a una compañía internacional» (Informe Mosconi, 2012: 18-19). Presumiblemente, la desregulación del mercado doméstico; el predominio dado por sus niveles de reservas comprobadas, volúmenes de producción y ventas de combustibles, así como la rentabilidad posibilitada por el «desgrase» de bienes menos lucrativos; podían convertirla en un activo seductor para el arribo de grandes inversores externos. Sin embargo, la española Repsol fue la única que concretó una propuesta de compra. ${ }^{27}$ Durante los noventa, la compañía había sido empujada a la competencia por la liberalización del mercado ibérico implicada en el ingreso del Esta-

25. Sus prerrogativas, sin embargo, no fueron efectivizadas por la sanción de una nueva ley sino hasta la década siguiente.

26. De este modo, podía reducir su tenencia del paquete accionario de la Clase A hasta una sola acción. En tal caso, su voto afirmativo continuaría siendo necesario para: autorizar la fusión de YPF SA con otras sociedades; aceptar que el $51 \%$ del capital fuera adquirido de manera hostil o consentida; transferir a terceros la totalidad de los derechos de explotación concedidos en el marco de la ley $\mathrm{n}^{\circ} 17.319 / 67$ y sus normas complementarias y reglamentarias; disolver voluntariamente YPF SA. Después de la ley no $24.474 / 95$ y las ventas que la sucedieron, el paquete accionario quedó repartido en un $65 \%$ en manos de inversores privados; un 20,3\% en propiedad del Estado nacional; un 4,7 \% para las provincias, y un $10 \%$ (bajo custodia del Estado) en manos del personal.

27. De las restantes interesadas en la oferta pública, la única empresa de envergadura fue BP - recientemente fusionada con Amoco e integrante de PAE en el país. La ausencia de otros grandes capitales es un indicio del lugar periférico que Argentina ocupaba en la estrategia de expansión de las empresas transnacionales, no solo en el caso de la industria hidrocarburífera, sino en el del conjunto de las privatizaciones. 
do español a la Comunidad Europea (Bosch Badía, 2008; Guillén Rodríguez, 2004; Sanchís, 1996). La compra de YPF fue el último paso de un proceso de reestructuración en el que se combinaron la expansión internacional y la racionalización de operaciones. En las condiciones mencionadas, los elevados retornos de la compañía argentina repagarían la inversión en un breve período de tiempo. ${ }^{28}$

En febrero de 1999, Repsol adquirió dicho 14,99 \% de las acciones a 38 dólares cada una. Ello significó un ingreso fiscal de poco más de 2.000 millones de dólares, utilizados para cubrir el déficit. En abril, la empresa española realizó una oferta pública por el resto del paquete accionario a 44,78 dólares el papel, que alcanzó una aceptación del 82,47 \%. Así, logró controlar el 97,46 \% del capital social por un desembolso total de 15.047 millones de dólares, más del doble que lo recaudado por el Estado en su desprendimiento de acciones. ${ }^{29}$ Gracias a esta compra, Repsol se convirtió en la novena petrolera del mundo y cuadruplicó sus reservas de petróleo y gas natural. ${ }^{30}$

Sumando a Gas del Estado, la privatización del sector hidrocarburífero representó el $52 \%$ de los ingresos fiscales obtenidos por el programa de reformas (Mansilla, 2007). También fue la más importante de acuerdo a los términos de la balanza de pagos. Entre 1992-2001, el rubro Petróleo concentró el 34,2\% del total de las transacciones de capital de la IED (26.200 millones de dólares), ${ }^{31}$ seguido por Industria manufacturera (21,2\%), Electricidad, Gas y Agua (12\%), Bancos (9,8 \%) y Transporte y Comunicaciones (9\%). Del total de la IED para el sector, un $66,8 \%$ se dirigió a la adquisición de empresas existentes, mientras que el porcentaje restante puede considerarse inversión genuina por aumento de la capacidad productiva (Caruso, 2003). Los beneficios obtenidos por estas inversiones se reflejan en la distribución de la renta de la IED. Entre 1992-1998, el sector Petróleo se apropió de un promedio del 22 $\%$ de la renta anual total de la IED — sumando 2.783 millones de dólares. Gracias al incremento de los precios internacionales, que se trasladó directamente al mercado interno, entre 1999-2001 ese ingreso alcanzó los 5.121 millones de dólares (Ministerio de Economía de la Nación; INDEC; Banco Central).

Después del desprendimiento final de las acciones de YPF, el Estado nacional pasó a captar renta hidrocarburífera solo a través del impuesto a las ganancias. El único mecanismo específico que se mantuvo fue el de las regalías, que, de acuerdo con la ley no 24.145/92 y la Constitución Nacional de 1994, benefician directamente a las provincias de donde se extraen los recursos. Según

28. Estos retornos fueron complementados por la venta de activos considerados no estratégicos, recortes del plan de inversiones 1999-2000 y la emisión de acciones y títulos convertibles.

29. En junio de ese año, el decreto no 666/99 autorizó la venta del resto de las acciones en manos del Estado Nacional, a excepción de la acción de oro. Según estima Kozulj (2002), las distintas etapas de reestructuración y privatización de YPF alcanzaron una recaudación total de 20.268 millones de dólares, de los cuales el Estado Nacional y las provincias percibieron un $39 \%$ y un $5 \%$, respectivamente.

30. Pasaron de 1.001 millones de barriles equivalentes de petróleo (BEP) a 4.698 millones BEP.

31. Solo la compra de acciones de YPF por Repsol significó un 19,6 \% del total. 
Gráfico 2. Producción anual y media diaria por pozo de petróleo (1970-2001)

Millones de $\mathrm{m}^{3}$

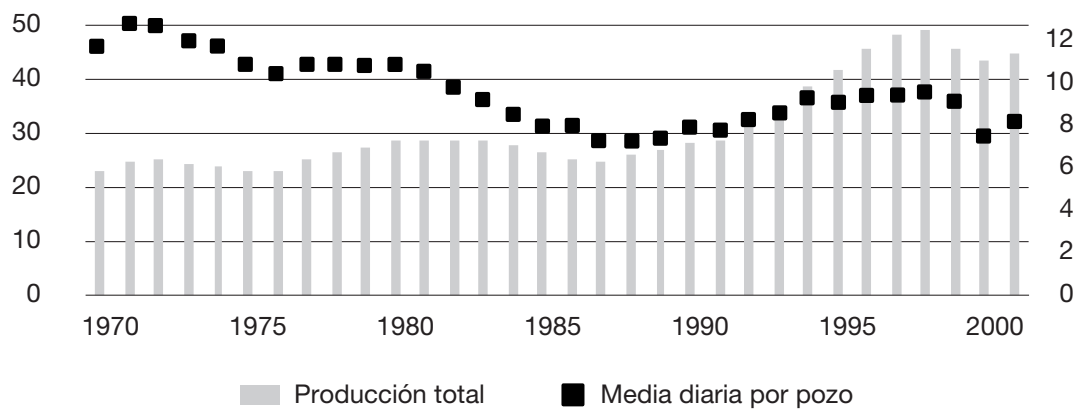

Fuente: elaboración propia en base a datos de Secretaría de Energía de la Nación.

cálculos de Mansilla (2007), en el período 1996-2001, las empresas del sector upstream se apropiaron de 15.642 millones de dólares; el Estado nacional se apropió de 9.138 millones de dólares; los estados provinciales de 3.854 millones; y las refinadoras y los consumidores de 2.144 millones.

$\mathrm{Al}$ igual que en otros sectores, la reestructuración neoliberal dinamizó la inversión e incorporación de tecnología. Como puede observarse en el gráfico 2 , en el caso del petróleo ello permitió revertir parcialmente una prolongada caída de la productividad, así como sostener un drástico incremento de la extracción.

Esta intensificación de la explotación obedeció a una aceleración de la monetización de las concesiones, en la que se expresó la lógica de la valorización abierta por las reformas neoliberales. Su efecto más notorio, como muestra el gráfico 3, fue un dramático e inédito crecimiento de las exportaciones - principalmente las de crudo sin elaboración, que alcanzaron un pico máximo del $41 \%$ de la producción en 1996.

En el caso del gas natural, después de una caída en 1990, la producción creció ininterrumpidamente hasta duplicar el volumen de 1989. Este incremento acompañó inicialmente la mayor demanda interna propiciada por el relanzamiento de la acumulación, para luego ser destinado a la exportación como producción excedente. A diferencia del petróleo, las ventas externas de gas comenzaron en 1997 e incrementaron su gravitación sobre el total de la extracción a medida que se desaceleraba el crecimiento de la oferta destinada al mercado interno. ${ }^{32}$

32. El carácter tardío de estas exportaciones a Chile, Uruguay y Brasil, así como sus menores volúmenes, se explica por la necesidad de grandes inversiones de capital para posibilitar su transporte. El gas natural no es commodity tradicional y carece de un mercado internacional de referencia como el de otras mercancías. Entonces, su comercialización se realizaba casi exclusivamente a través de gasoductos y mediante contratos a largo plazo. 
Gráfico 3. Exportaciones de crudo y derivados (1989-2001)

Millones de $\mathrm{m}^{3} \mathrm{o}$ tn

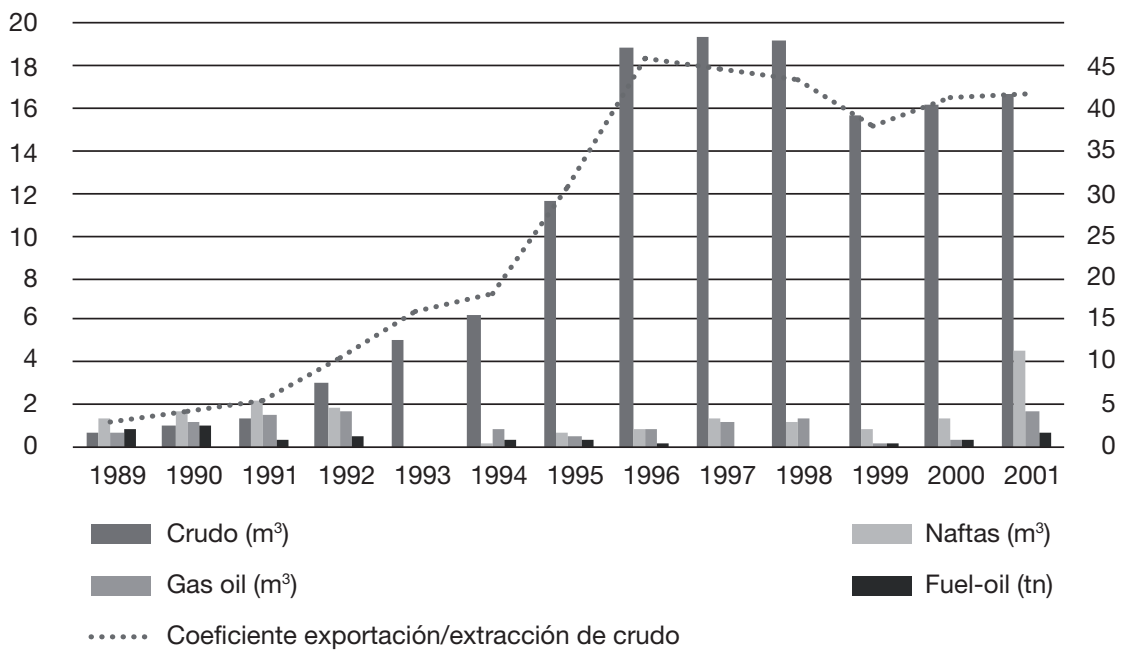

Fuente: elaboración propia en base a datos de Secretaría de Energía de la Nación.

Exacerbada por la internacionalización de la competencia, la lógica de la valorización se expresó, asimismo, en el carácter insuficiente de la inversión destinada a la reposición de reservas. En primer lugar, aunque la perforación de pozos exploratorios tuvo un comportamiento irregular, desde mediados de los noventa se produjo una marcada declinación de su porcentaje con relación al total. Entre 1993-1996, la consolidación del proceso de reestructuración del sector dio paso a un breve período de «auge» exploratorio, durante el cual se alcanzó el máximo anual de perforaciones y creció notablemente la participación de los capitales privados. A partir de 1997, sin embargo, tuvo lugar una importante merma en las perforaciones exploratorias llevadas adelante por YPF, que fue posteriormente acompañada por el resto de las empresas. Este comportamiento no puede abstraerse de los factores internos y externos que desencadenaron la crisis de la convertibilidad, así como de la abrupta caída de las cotizaciones internacionales ocurrida entre 1997-1999.

En segundo lugar, también existe evidencia de que la exploración tendió a concentrarse sobre las cuencas y áreas de potencial comprobado. De acuerdo al relevamiento de los 87 permisos exploratorios concedidos durante las rondas licitatorias del período 1992-2001 del Plan Argentina, tan solo el 30 \% correspondió a áreas ubicadas en cuencas no productivas. La prioridad dada a cuencas más conocidas - especialmente la Neuquina - explica el notable incremento en la proporción de pozos de exploración productivos de petróleo y gas. Ese grado de éxito, que durante los ochenta alcanzó un promedio del $35 \%$, se elevó del $25 \%$ al $70 \%$ entre 1989-1992, para luego mantenerse 
Gráfico 4. Extracción de gas natural por destino (1989-2001)

Millones de $\mathrm{m}^{3} \mathrm{o}$ tn

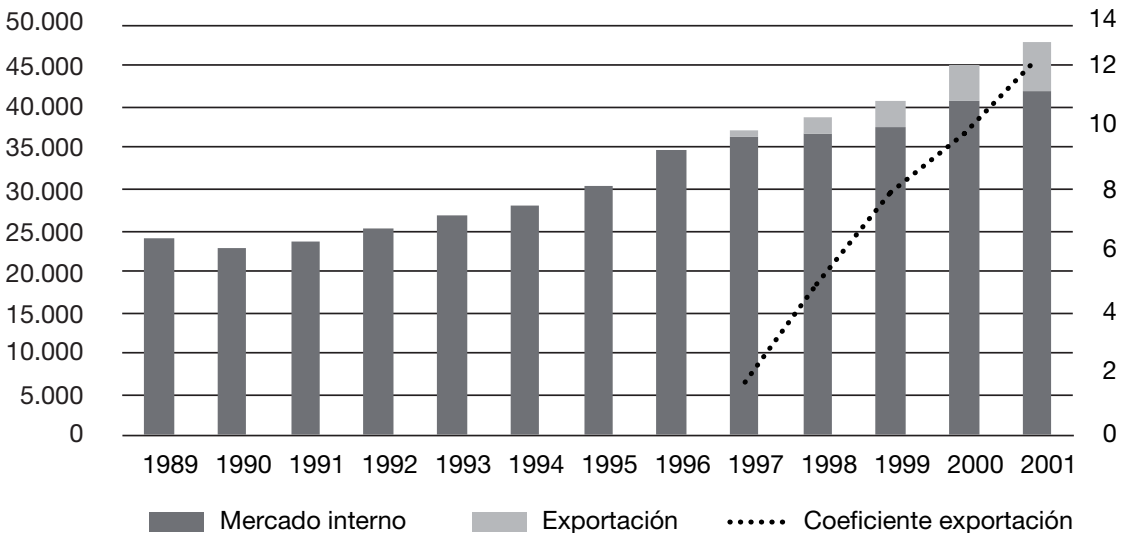

Fuente: elaboración propia en base a datos de Secretaría de Energía de la Nación.

Gráfico 5. Pozos de exploración, avanzada y explotación (1989-2001)

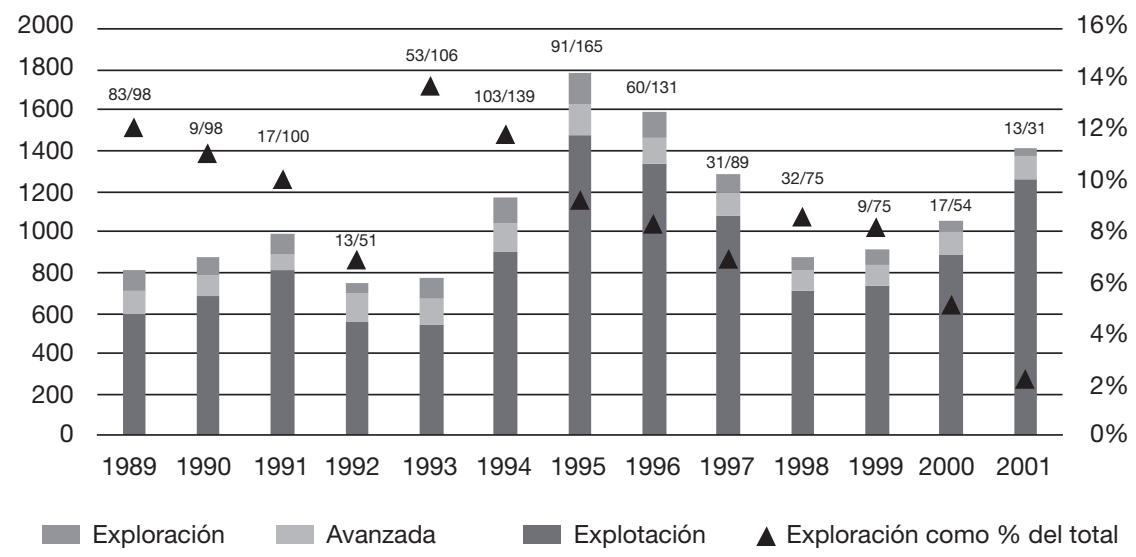

Fuente: elaboración propia en base a datos de Secretaría de Energía de la Nación.

relativamente estable en una proporción del 50 \% (Anuarios de Combustibles; Secretaría de Energía de la Nación). Si bien ello determinó un importante crecimiento del número anual de hallazgos, una parte cada vez mayor de esta incorporación de reservas — sobre todo en el caso del petróleo- se produjo gracias a campos puestos en producción con anterioridad a 1990. Durante la segunda mitad de la década, pues, también tendieron a disminuir los metros cúbicos adicionados por descubrimiento (Cruz, 2005). 
Gráfico 6. Exportación de combustibles según índices de valor, precio y cantidad (1990-2001) Índice

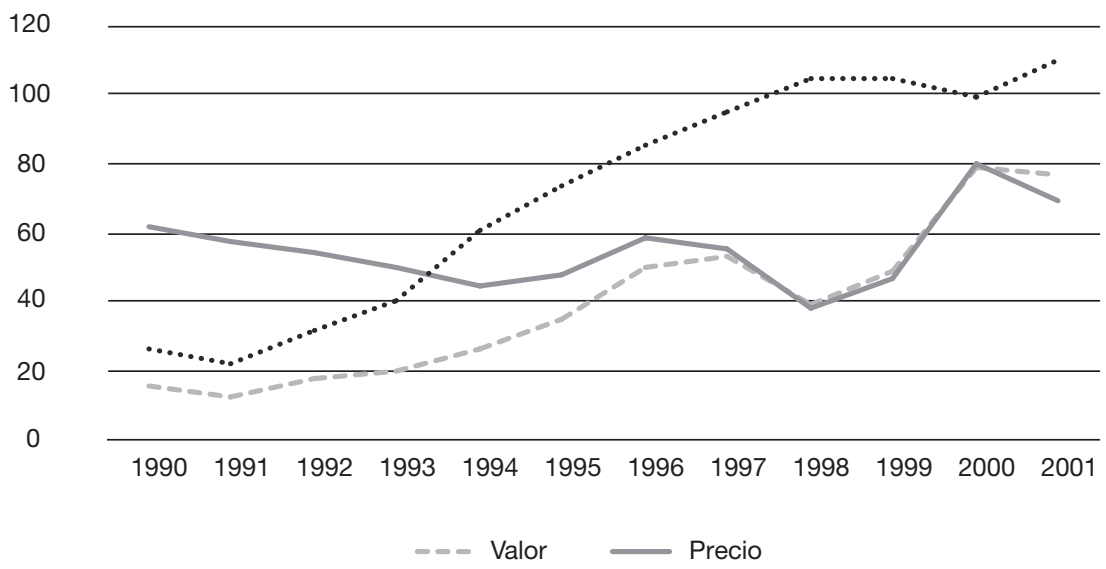

Fuente: elaboración propia en base a datos de INDEC.

Como consecuencia general, en el período 1989-2001 los incrementos de la producción no fueron acompañados por la evolución de las reservas comprobadas. En el caso del petróleo, las reservas crecieron un 32,8 \%, de $344 \mathrm{Mm}^{3}$ a $457 \mathrm{Mm}^{3}$. A raíz de este menor dinamismo, el «horizonte de reservas» se redujo de casi 13 a poco más de 10 años. En el caso del gas natural, después de una evolución irregular, las reservas alcanzaron una magnitud similar a la de 1989, con un volumen de $763.000 \mathrm{Mm}^{3}$. De esta manera, el horizonte se contrajo a la mitad, de 31 a 16 años.

En términos agregados, las exportaciones de combustibles fueron las más dinámicas de la convertibilidad, multiplicando su cantidad por cuatro entre 1990-2001. El incremento del volumen de las ventas externas se desarrolló con independencia de la variación de los precios internacionales y su tendencia decreciente a lo largo de los noventa.

Entre 1991-2001, las exportaciones FOB de Combustibles y energía pasaron de 765 millones de dólares a 4.724 millones. De esta manera, se produjo una reversión de la histórica tendencia a acumular déficits en la balanza comercial energética por las dificultades para lograr el autoabastecimiento y, en toda la etapa, el saldo de los intercambios externos fue positivo. ${ }^{33}$

Como resultado, las ventas de Combustibles y energía incrementaron su gravitación sobre el total de las exportaciones FOB. Durante el ciclo de auge

33. Según datos de los Anuarios de Combustibles, en las décadas del sesenta, setenta y ochenta (hasta 1988), el saldo negativo anual promedio de la balanza comercial energética fue de 73 millones de dólares, 337,1 millones y 213,6 millones. Entre 1989-2001, en cambio, se alcanzó un saldo positivo anual promedio de 1.634 millones de dólares, con picos de 3.800 millones en 2000 y 2001. 
1991-1998, promediaron una participación del $11 \%$; si consideramos la etapa de punta a punta, pasaron de representar un $4 \%$ a un $18 \%$ del total. En la apertura de la categoría puede advertirse una tendencia primarizadora, dada por el retroceso relativo de las exportaciones de bienes de mayor valor agregado. Entre 1991-2001, las exportaciones FOB de Petróleo crudo y de Gas de petróleo y otros hidrocarburos incrementaron su participación del 19,2 \% al 50 \% y del 3,7 \% al 12,9\%, respectivamente. Si bien las ventas de Carburantes, grasas y aceites lubricantes crecieron en términos absolutos durante el mismo período, su incidencia sobre el total se redujo del $69,5 \%$ al 31,6\%.

\section{Una articulación compleja con consecuencias de largo plazo}

Hemos planteado que la salida de la crisis hiperinflacionaria de 1989 dio resolución a un prolongado y complejo proceso de reestructuración capitalista en el que se entrelazaron factores externos e internos. En su determinación más general, como ha sido trabajado desde diferentes perspectivas en la abundante literatura existente acerca de las reformas neoliberales (Azpiazu y Basualdo, 2004; Bonnet, 2007; Boron, 2003a; 2003b; Dinerstein, 1993; Haggard y Kaufman, 1995; Oszlak, 2003; Thwaites Rey, 1994; 1995; Torre, 1998; entre otros), dicha reestructuración supuso una amplia incorporación de relaciones sociales a ser mediadas por las compulsiones del mercado. Nuestro análisis de las características y contradicciones de la nueva «estrategia de acumulación» indica que, en el ámbito de la producción, tuvo lugar una modernización y reorientación exportadora de las ramas más competitivas del aparato industrial. La política hidrocarburífera del Estado se vio inmediatamente confrontada, de tal suerte, con las necesidades de un modelo de crecimiento económico basado en la producción que tendió a magnificar el consumo de energía. Y ello, en un marco dado por la desregulación del mercado doméstico, la privatización de activos públicos y la apertura del espacio nacional a la acción de la ley del valor a escala mundial.

En este sentido, nuestro trabajo dialoga con los análisis sociológicos más difundidos acerca las transformaciones neoliberales en Argentina, a la vez que se distancia de los mismos en dos aspectos fundamentales. Por un lado, cuestionamos el carácter orgánico de la reestructuración del sector hidrocarburífero respecto de un nuevo régimen de acumulación sustentado por la «valorización financiera» y la primarización de la economía. Esa es una lectura predominante entre los estudios de sociología económica del período (Azpiazu y Nochteff, 1994; Basualdo, 2000; 2006; 2011; Schvarzer, 1998; entre otros), a partir de la cual se plantea que la comoditización de los recursos, en oposición a su apropiación «estratégica» durante la ISI, habría sido funcional «al plan extranjerizador y de abandono de las bases productivas de la economía» (Mansilla, 2007: 116). Por el otro, retomando perspectivas de la sociología política cuyo punto de partida epistemológico es la internacionalización (Hirsch, 1992, 1996; Jessop, 2002; Negri, 2004; entre otros), entendemos que el centro de la cuestión no reside ya en la puja entre distintas fracciones del capital por la asignación 
de costos y beneficios derivados del cambio de modelo económico (Barrera, 2014; Barrera et al., 2012; Sabbatella, 2013), ${ }^{34}$ sino en la articulación global de la acumulación, la competencia en el mercado mundial y la redefinición de la relación Estado-capital.

En las condiciones planteadas por el estallido hiperinflacionario, tanto la crisis fiscal como el quebranto de las empresas públicas limitaban las capacidades del Estado para garantizar la provisión infraestructural-energética de un eventual relanzamiento de la acumulación. El proceso posterior, en el que se ha visto una "colusión de intereses» con el capital privado, la colonización de reductos estatales para el diseño de políticas o la formación de «ámbitos privilegiados de acumulación» (Serrani, 2012; Serrani y Castellani, 2011), se encuentra definido, desde nuestra perspectiva, por la necesidad de potenciar la inversión privada con los propósitos de asegurar el abastecimiento interno de combustibles e incrementar la disponibilidad de divisas de la economía. Naturalmente, ello supuso que el aprovechamiento de los hidrocarburos como objetos de uso quedase subordinado, ipso facto, a las posibilidades de desenvolvimiento de la lógica del valor en el sector hidrocarburífero. En otras palabras, a partir de aquí, la comoditización se convertiría en condición necesaria para la apropiación social del petróleo y el gas en cuanto que «recursos estratégicos».

La transformación cualitativa de la industria petrolera fue un aspecto del proceso de reestructuración capitalista y metamorfosis estatal de la convertibilidad (Bonnet, 2008; Piva, 2012). Como tal, gravitó inicialmente en la recuperación de competencias fiscales y de intervención del Estado, así como en la reconstitución de la legitimidad política. Luego, no solo posibilitó el aseguramiento de la oferta interna de energía, sino que también propició el ingreso de un importante caudal de divisas por exportaciones o a través de la cuenta capital. Así pues, tanto la operatoria del sector como el progresivo desprendimiento de acciones de YPF y el arribo de otros capitales internacionales contribuyeron a morigerar los desequilibrios externos y fiscales de la «estrategia de acumulación».

En este mismo plano, la imposición de la mediación dineraria en todos los segmentos de la actividad, así como la igualación de los precios locales con los internacionales a partir de la eliminación de subsidios y regímenes especiales, vehiculizó mecanismos de disciplinamiento implícitos en la restricción monetaria, la desregulación y la apertura indiscriminada de la economía. Si durante el modelo de la ISI el manejo "político» del precio de los combustibles había subsidiado económicamente al capital, ahora el libre juego de la oferta y la demanda descargaba con más fuerza aún el peso del mercado mundial sobre la economía nacional. Así, reforzaba la necesidad de que la producción local ganara competitividad a través de transformaciones técnicas, la reorganización de los procesos productivos y una mayor explotación de la fuerza de trabajo.

34. Lectura en la que, a su vez, una serie de relaciones asumen un carácter pretendidamente antinómico: Estado/mercado; capital productivo/capital financiero; producción industrial/ producción primaria y servicios; burguesía nacional/«oligarquía diversificada»/capital y acreedores extranjeros. 
En tanto, como parte de un proceso global y de largo plazo, las políticas neoliberales introdujeron en el espacio nacional tendencias dadas por la reestructuración y la desintegración vertical de los capitales petroleros, su interpenetración en joint ventures con el Estado y la expansión mundial en búsqueda de nuevas reservas y mercados. Así pues, el aspecto definitorio de la transformación cualitativa impulsada a partir de 1989 fue la conversión del sector hidrocarburífero argentino en un escenario más de la competencia mundial. En un mismo movimiento, las fracciones locales de la burguesía fueron «compensadas» por la desarticulación del sistema de contratos con el Estado a través de YPF y lanzadas a competir en la arena internacional. De aquí se explica que fueran forzadas a emprender estrategias de expansión — particularmente a nivel regional-, así como que luego vieran sus negocios absorbidos por capitales más concentrados.

Ahora bien, la misma lógica que permitió potenciar la inversión y alcanzar el autoabastecimiento exasperó la extracción y la exportación de recursos. Puestos en manos de los capitales petroleros, los hidrocarburos pasaron a tener valor de uso únicamente como portadores de valor. Consecuentemente, la planificación y la organización de su explotación quedaron primariamente ordenadas por la maximización de ganancias. Sin embargo, este usufructo en cuanto que commodity en ningún momento desvaneció el carácter «estratégico» del petróleo y el gas, si por ello nos referimos a sus propiedades naturales como valores de uso.

Como demostramos, la reestructuración neoliberal del capital magnificó el consumo de energía en la producción y circulación de mercancías. Los hidrocarburos siguieron subsidiando energéticamente la explotación de la fuerza de trabajo y la apropiación de la naturaleza, así como la reproducción de la sociedad en su conjunto. Por esta razón, en su dimensión material, las transformaciones y políticas implementadas en el sector se articularon complejamente con las características de la «estrategia de acumulación». Si, por un lado, posibilitaron el mantenimiento de la oferta energética, por el otro, supusieron la despolitización de la gestión global de los recursos. El sometimiento de las inversiones a la inmediatez de la lógica internacional del valor se tradujo en un desarrollo de la producción que rebasó las necesidades del mercado interno y que no tuvo contrapartida en los esfuerzos dedicados al cateo y la exploración. De esta manera, la colocación en el mercado mundial de las reservas comprobadas durante décadas por la vieja YPF estatal aceleró la maduración de los principales yacimientos y tendió a socavar los fundamentos "termodinámicos" del corazón de la acumulación. Después de todo, como dice el adagio tantas veces repetido, "Argentina es un país con petróleo y no un país petrolero».

\section{Conclusiones}

Con el propósito de contribuir a la comprensión de las transformaciones cualitativas experimentadas por la industria petrolera argentina en el marco de las reformas neoliberales, hemos analizado las políticas de reestructuración del 
sector hidrocarburífero en su articulación con las principales características de la "estrategia de acumulación» durante la etapa dominada por la convertibilidad (1989-2001). La consecución de este objetivo obedeció a nuestro interés por superar los valiosos estudios que nos anteceden, asimilando sus resultados más significativos en la consideración de contradicciones y procesos sociales de mayor alcance. De modo tal que, mediante una matriz interdisciplinaria y multimétodo inspirada en los estudios de políticas estatales, operamos un desplazamiento de la perspectiva de análisis a fin de incorporar como presupuestos la internacionalización del capital y sus implicancias en el desarrollo de los fenómenos económico-políticos.

El estudio de las principales características de la «estrategia de acumulación» se basó en las herramientas intelectuales y los procedimientos de la sociología económica. Esta parte del trabajo posibilitó la construcción del contexto agregado de nuestro análisis, fundamental para la comprensión, descripción, explicación y evaluación de las políticas neoliberales aplicadas al sector hidrocarburífero. Discutimos, entonces, con las tesis más difundidas acerca de una supuesta "financiarización» o "primarización» del modelo económico, oponiéndoles el carácter "capital-intensivo» de la reestructuración, así como la reorientación exportadora del aparato industrial. Un indicador adicional que avala estos resultados es, como vimos, el crecimiento y la dinámica sectorial de la demanda energética.

En este marco, el análisis de las políticas implementadas en el sector hidrocarburífero demuestra que la intervención estatal tuvo como motivaciones primarias el abastecimiento interno de energía para un nuevo modelo de crecimiento, así como la obtención de saldos exportables que contrarrestaran el crónico déficit de divisas de la economía. Ahora bien, en un contexto dado por la crisis de la «estrategia de acumulación" previa y sus impactos sobre las capacidades del Estado, dicha intervención adoptó la forma de un impulso a la inversión privada que supuso la amplia desregulación y apertura del mercado a la competencia internacional. Las consecuencias inmediatas de la puja entre fracciones del «bloque en el poder» fueron, en realidad, un aspecto transitorio del desenvolvimiento de ese proceso.

Vimos, entonces, que la introducción de la lógica del valor como presupuesto de la apropiación de los hidrocarburos en cuanto que objetos de uso no solo exasperó la producción, sino que también entrelazó el carácter de la inversión a las estrategias de internacionalización y las constricciones competitivas que debían enfrentar los diversos capitales. Como consecuencia, se aceleró la extenuación de los principales campos petroleros y tuvo lugar un marcado descenso del «horizonte de reservas». Este problema permaneció latente durante la convertibilidad, solo presentándose como dilema a conjurar por la política petrolera del Estado a partir de 2002.

En la nueva etapa, una serie de cambios «tácticos» de la «estrategia de acumulación», entrelazados con la reversión de la tendencia secular de los precios en el mercado mundial, dieron lugar a una recomposición del ciclo económico que relanzó el consumo interno de energía. Dada la maduración de los reser- 
vorios sobre los que debían operar en el país, así como la internacionalización de sus portfolios, las compañías petroleras comenzarían a demandar garantías respecto de la situación institucional, la libertad de mercado y la implementación de distintos estímulos para dinamizar nuevamente la inversión. Estas aspiraciones - especialmente las de naturaleza económica - entrarían en contradicción con la separación entre espacios de valor y los límites a la acción de los capitales planteados por la implementación del sistema de derechos de exportación de hidrocarburos a partir de 2002. Siguiendo las conclusiones del presente artículo, puede proponerse a modo de nueva hipótesis de trabajo que, durante la posconvertibilidad, el Gobierno nacional enfrentaría un desafío aparentemente irresoluble: lanzar exitosamente la geología argentina a la competencia mundial, pero evitando aquellas concesiones a la inversión internacional de alto riesgo que pudieran desequilibrar drásticamente los fundamentos de la «estrategia de acumulación» posconvertibilidad.

\section{Referencias bibliográficas}

Abdalla, Kathleen (1995). "The changing structure of the international oil industry». Energy Policy, 23 (10), 871-877. <https://doi.org/10.1016/0301-4215(95)98710-A>.

Acuña, Carlos (1995). La nueva matriz politica en la Argentina. Buenos Aires: Nueva Visión.

Aglietta, Michel (1986). Regulación y crisis del capitalismo. La experiencia de los Estados Unidos. Madrid: Siglo XXI Editores de España.

Alexander, Myrna; Corti, Carlos (1993). Argentina's Privatization Program. Washington DC: Banco Mundial.

Altvater, Elmar (1977). «Notas sobre algunos problemas del intervencionismo de Estado». En: Sonntag, Heinz Rudolf; Valecillos, Héctor (eds.). El Estado en el capitalismo contemporáneo. México DF: Siglo XXI Editores.

Anderson, Perry (2003). «Neoliberalismo: un balance provisorio». En: EMIR, Sader; Gentili, Pablo (eds.). La trama del neoliberalismo. Mercado, crisis y exclusión social. Buenos Aires: CLACSO.

Arrighi, Giovanni (1999). El largo siglo XX. Madrid: AKAL.

Astarita, Rolando (2004). Valor, mercado mundial y globalización. Buenos Aires: Ediciones Cooperativas.

Azpiazu, Daniel; Nochteff, Hugo (1994). El desarrollo ausente. Restricciones al desarrollo, neoconservadorismo y élite económica en la Argentina. Ensayos de economía política. Buenos Aires: FLACSO-Grupo Editorial Norma.

Azpiazu, Daniel; Basualdo, Eduardo; Schorr, Martín (2001). La industrialización argentina durante los años noventa: profundización y consolidación de los rasgos centrales de la dinámica sectorial post-sustitutiva. Buenos Aires: FLACSO.

Azpiazu, Daniel; Basualdo, Eduardo; Khavisse, Miguel (2003). El nuevo poder económico en la Argentina de los 80. Buenos Aires: Siglo XXI Editores.

Azpiazu, Daniel; Basualdo, Eduardo (2004). "Las privatizaciones en la Argentina. Genesis, desarrollo y principales impactos estructurales». En: Petras, James; VeLTMEYER, Henry (eds.). Las privatizaciones y la desnacionalización de América Latina. Buenos Aires: Prometeo Libros. 
Barreau, Sebastien (2002). «Innovations and External Growth Strategy: the Case of Oil and Gas Supply and Service Companies». Oil \& Gas Science and Technology, 57 (2), 193-203. <https://doi.org/10.2516/ogst:2002015>.

Barrera, Mariano (2014). La entrega de YPF. Análisis del proceso de privatización de la empresa. Buenos Aires: Centro Cultural de la Cooperación - Atuel.

Barrera, Mariano; Sabbatella, Ignacio; Serrani, Esteban (2012). Historia de una privatización. Cómo y por qué se perdió YPF. Buenos Aires: Capital Intelectual.

Basualdo, Eduardo (2000). Concentración y centralización del capital en la Argentina durante la década del noventa. Bernal: Universidad Nacional de Quilmes EdicionesFLACSO-IDEP.

- (2006). Estudios de historia económica argentina. Desde mediados del siglo XX a la actualidad. Buenos Aires: Siglo XXI Editores.

- (2011). Sistema político y modelo de acumulación. Tres ensayos sobre la Argentina actual. Buenos Aires: Atuel.

Bina, Cyrus; Yaghmaian, Behzad (1991). «Post-war Global Accumulation and the Transnationalisation of Capital». Capital \& Class (43), 107-130.

Bonefeld, Werner (1995). «Dinero y libertad. El poder constitutivo del trabajo y la reproducción capitalista». Cuadernos del Sur (ed.). Globalización y Estados-nación. El monetarismo en la crisis actual. Buenos Aires: Editorial Tierra del Fuego-Homo Sapiens Ediciones.

BonneT, Alberto (2002). «El fetichismo del capital dinero. Un comentario sobre el debate Chesnais-Husson». Revista Sociedade Brasileira de Economia Politica (8), 49-79.

- (2007). «Políticas neoliberales y lucha de clases». En: Bonefeld, Werner; Bonnet, Alberto; Holloway, John; Tischler, Sergio (eds.). Marxismo abierto, volumen II. Buenos Aires: Benemérita Universidad Autónoma de Puebla-Herramienta.

- (2008). La hegemonía menemista. El neoconservadurismo en Argentina, 1989-2001. Buenos Aires: Prometeo Libros.

Bonnet, Alberto; Glavich, Eduardo (1993). "El huevo y la serpiente. Notas acerca de la crisis del régimen democrático de dominación y la reestructuración capitalista en Argentina, 1983-1993» (Primera parte). Cuadernos del Sur (16), 9-29.

- (1994). «El huevo y la serpiente. Notas acerca de la crisis del régimen democrático de dominación y la reestructuración capitalista en Argentina, 1983-1993 (Segunda parte)». Cuadernos del Sur (17), 13-33.

Boron, Atilio (2003a). Estado, capitalismo y democracia en América Latina. Buenos Aires: CLACSO.

- (2003b). «La sociedad civil después del diluvio neoliberal». En: SAder, Emir; Gentili, Pablo (eds.). La trama del neoliberalismo. Mercado, crisis y exclusión social. Buenos Aires: CLACSO.

Bosch Badía, María Teresa (2008). «Repsol: De empresa pública a multinacional del petróleo». Información Comercial Española (842), 217-234.

Caruso, Nicolás (2003). Estudios sectoriales. Componente: Gas natural y derivados. Buenos Aires: CEPAL.

Castellani, Ana (2009). Estado, empresas y empresarios. La conformación de ámbitos privilegiados de acumulación entre 1966 y 1989. Buenos Aires: Prometeo Libros.

Cruz, Carlos Enrique (2005). «El gran desafío de ampliar las fronteras de la exploración». Petrotecnia, 45 (6), 8-26.

Dinerstein, Ana (1993). «Privatizaciones y legitimidad: la lógica de la coerción». Realidad Económica (113), 18-30. 
Gadano, Nicolás (1998). Determinantes de la inversión en el sector petróleo y gas de la Argentina. Santiago de Chile: CEPAL.

- (2006). Historia del petróleo en la Argentina. Buenos Aires: Edhasa.

Gerchunoff, Pablo (1994). Privatización y desregulación del sector petrolero en Argentina. Santiago de Chile: CEPAL.

Gigliani, Guillermo; Bercovich, Alejandro (2006). «Productividad y salarios industriales en la "era Kirchner"». Anuario EDI (2), 86-101.

Grigera, Juan (2011). "La desindustrialización en Argentina. ¿Agresión a la manufactura o reestructuración capitalista?» En: Bonnet, Alberto (ed.). El país invisible. Debates sobre la Argentina reciente. Buenos Aires: Peña Lillo-Ediciones Continente.

- (2013). «El concepto de desindustrialización como peculiaridad argentina». Revista de Estudios Maritimos y Sociales (5/6), 187-195.

Grossmann, Henryk (1979). Ensayos sobre la teoría de las crisis. México DF: Ediciones Pasado y Presente.

Guillén RodríGuez, Mauro (2004). «La internacionalización de las empresas españolas». Información Comercial Española (812), 211-224.

Haggard, Stephan; Kaufman, Robert (1995). «Estado y reforma económica: la iniciación y consolidación de las políticas de mercado». Desarrollo Económico, 35 (139), 355-372. <https://doi.org/10.2307/3467206>.

Hardt, Michael; Negri, Antonio (2002). Imperio. Barcelona: Paidós.

Harvey, David (2005). A Brief History of Neoliberalism. Nueva York: Oxford University Press.

- (2007). Espacios del capital: Hacia una geografía critica. Madrid: AKAL.

- (2008). La condición de la posmodernidad. Investigación sobre los orígenes del cambio cultural. Buenos Aires: Amorrortu Editores.

Hirsch, Joachim (1978). "The State Apparatus and Social Reproduction: Elements of a Theory of the Bourgeois State». En: Holloway, John; Picciotto, Sol (eds.). State and Capital. A Marxist Debate. Londres: Edward Arnold.

- (1992). "Fordismo y posfordismo. La crisis social actual y sus consecuencias». En: Bonefeld, Werner; Holloway, John (eds.). Los estudios sobre el Estado y la reestructuración capitalista. Buenos Aires: Editorial Tierra del Fuego.

- (1996). Globalización, capital y Estado. México DF: Universidad Autónoma Metropolitana.

Holloway, John (1994). Marxismo, Estado y capital. Buenos Aires: Editorial Tierra del Fuego.

INFORME MOSCONI (2012). Ministerio de Planificación Federal, Inversión Pública y Servicios; Ministerio de Economía y Finanzas Públicas.

Jessop, Bob (1991). «Accumulation Strategies, State Forms and Hegemonic Projects». En: Clarke, Simon (ed.). The State Debate. Londres: Palgrave Macmillan UK. <https://doi.org/10.1007/978-1-349-21464-8>.

- (2002). The Future of the Capitalist State. Cambridge: Polity Press.

Kaplan, Marcos (1992). Estudios sobre politica y derecho del petróleo argentino (19071955). México DF: Universidad Nacional Autónoma de México.

Kцаснко, Paula (2002). "La conflictividad social en la Argentina de los '90: el caso de las localidades petroleras de Cutral Có y Plaza Huincul (1996-1997)». En: Levy, Bettina (ed.). Crisis y conflicto en el capitalismo latinoamericano: Lecturas politicas. Buenos Aires: CLACSO. 
Kosacoff, Bernardo (1993). «La industria argentina: un proceso de reestructuración desarticulada». En: Kosacoff, Bernardo (ed.). El desafio de la competitividad. La industria argentina en transformación. Buenos Aires: Alianza Editorial.

Kozulj, Roberto (2002). Balance de la privatización de la industria petrolera en Argentina y su impacto sobre las inversiones y la competencia en los mercados minoristas. Santiago de Chile: CEPAL.

KozUlJ, Roberto; Bravo, Víctor (1993). La política de desregulación petrolera argentina. Antecedentes e impactos. Buenos Aires: Centro Editor de América Latina.

Kulfas, Matías; ScHORR, Martín (2000). Concentración en la industria manufacturera argentina durante los años noventa. Buenos Aires: FLACSO.

LabBan, Mazen (2010). «Oil in parallax: Scarcity, markets, and the financialization of accumulation». Geoforum, 41 (4), 541-552. <https://doi.org/10.1016/j.geoforum.2009.12.002>.

Lipietz, Alain (1986). "New Tendencies in the International Division of Labour: Regimes of Accumulation and Modes of Regulation». En: Scotт, Allen J.; STORPER, Michael (eds.). Production, Work, and Territory: The Geographical Anatomy of Industrial Capitalism. Boston: Allen \& Unwin.

Mansilla, Diego (2007). Hidrocarburos y politica energética. De la importancia estratégica al valor económico: desregulación y privatización de los hidrocarburos en Argentina. Buenos Aires: Ediciones del CCC.

Marticorena, Clara (2013). "Relaciones laborales y condiciones de trabajo en la industria manufacturera durante la posconvertibilidad». En: Grigera, Juan (ed.). Argentina después de la convertibilidad (2002-2011). Buenos Aires: Ediciones Imago Mundi.

Martínez, Ricardo; Lavarello, Pablo; Heymann, Daniel (1998). Inversiones en la Argentina. Aspectos macroeconómicos y análisis del destino de los equipos importados. Buenos Aires: CEPAL.

Mitchell, Timothy (2011). Carbon Democracy. Political Power in the Age of Oil. Nueva York: Verso.

NegRI, Antonio (2004). Los libros de la autonomía obrera. Madrid: AKAL.

Oszlak, Oscar (2003). «El mito del estado mínimo: una década de reforma estatal en la Argentina». Desarrollo Económico, 42 (168), 519-543.

Oszlak, Oscar; O’Donnell, Guillermo (1995). «Estado y políticas estatales en América Latina: hacia una estrategia de investigación». Redes, 2 (4), 98-128.

Palloix, Christian (1975). Las firmas multinacionales y el proceso de internacionalización. Madrid: Siglo XXI Editores de España.

Petruccelli, Ariel (2005). Docentes y Piqueteros. De la huelga de ATEN a la pueblada de Cutral Có. Buenos Aires: El Cielo por Asalto-El Fracaso.

Pistonesi, Héctor (2001). Desempeño de las industrias de electricidad y gas natural después de las reformas: el caso de Argentina. Santiago de Chile: ILPES-CEPAL.

Piva, Adrián (2012). Acumulación y hegemonia en la Argentina menemista. Buenos Aires: Biblos.

- (2015). Economía y politica en la Argentina kirchnerista. Buenos Aires: Batalla de Ideas.

Poulantzas, Nicos (2001). Poder político y clases sociales en el Estado capitalista. Buenos Aires: Siglo XXI Editores.

Roberts, Paul (2004). The End of Oil. Nueva York: Houghton Mifflin Company.

Robinson, William; Harris, Jerry (2000). «Towards a Global Ruling Class? Globalization and the Transnational Capitalist Class». Science \& Society, 64 (1), 11-54. 
Rodríguez-Padilla, Víctor (1991). «Sovereignty Over Petroleum Resources: The End of an Era?». Energy Studies Review, 3 (2), 108-123. $<$ https://doi.org/10.15173/esr.v3i2.237>.

Rosdolsky, Roman (2004). Génesis y estructura de El Capital de Marx. México DF: Siglo XXI Editores.

Sabbatella, Ignacio (2013). ¿Commodities o bienes estratégicos para el crecimiento económico? La ecología política del petróleo y gas en la etapa posneoliberal. Universidad de Buenos Aires.

Salvia, Sebastián; Frydman, Axel (2004). «Modo de acumulación y relaciones de fuerza entre capital y trabajo en la Argentina de los noventa». Herramienta (26).

SANCHís, Juan Alberto (1996). «Privatización y eficiencia en el sector público español». Revista de Economía Aplicada, 4 (10), 65-92.

Schorr, Martín (2000). «Principales rasgos de la industria argentina tras una década de ajuste estructural». Realidad Económica (170), 1-36.

SChVARZER, Jorge (1998). Implantación de un modelo económico. La experiencia argentina entre 1975 y el 2000. Buenos Aires: AZ-Editora.

SERrANi, Esteban (2012). Estado, empresarios y acumulación privilegiada de capital. Análisis de la industria petrolera argentina (1988-2008). Universidad de Buenos Aires.

Serrani, Esteban; Castellani, Ana (2011). «Reformas estructurales y acumulación privilegiada de capital. El caso del mercado petrolero argentino durante los años noventa». En: Pucciarelli, Aldo (ed.). Los años de Menem. La construcción del orden neoliberal. Buenos Aires: Siglo XXI Editores.

SidicARo, Ricardo (2010). La crisis del Estado y los actores políticos y socioeconómicos en la Argentina (1989-2001). Buenos Aires: EUDEBA.

Thwaites Rey, Mabel (1994). "Qué Estado después del estatalismo. La política de privatizaciones en Argentina (1984-1993)». En: El rediseño del perfil del Estado. Buenos Aires: Publicaciones de la Secretaría de Posgrado de la Facultad de Ciencias Económicas de la Universidad de Buenos Aires.

- (1995). «El rediseño de la relación Estado-sociedad: la política de privatizaciones en Argentina (1989-1995)». Gestión y Análisis de Políticas Públicas (3), 91-104.

- (2003). La (des)ilusión privatista. El experimento neoliberal en la Argentina. Buenos Aires: EUDEBA.

Toledo Tolentino, Ángel (2011). «Cambios en la industria petrolera internacional bajo la etapa neoliberal». En: Márquez Covarrubias, Humberto; Soto Esquivel, Roberto; Záyago Lau, Édgar (eds.). El desarrollo perdido. Avatares del capitalismo neoliberal en tiempos de crisis. México DF: Miguel Ángel Porrua-UAZ.

Torre, Juan Carlos (1998). El proceso politico de las reformas económicas en América Latina. Buenos Aires: Paidós.

Yaghmaian, Behzad (1998). "Globalization and the State: The Political Economy of Global Accumulation and Its Emerging Mode of Regulation». Science \& Society, 62 (2), 241-265.

Yergin, Daniel. (2008). The Prize. Nueva York: Free Press. 